\title{
Aberrant Synaptic Integration in Adult Lamina I Projection Neurons Following Neonatal Tissue Damage
}

\author{
Jie Li, Delizabeth Kritzer, Paige E. Craig, and Mark L. Baccei \\ Pain Research Center, Department of Anesthesiology, University of Cincinnati Medical Center, Cincinnati, Ohio 45267
}

\begin{abstract}
Mounting evidence suggests that neonatal tissue damage evokes alterations in spinal pain reflexes which persist into adulthood. However, less is known about potential concomitant effects on the transmission of nociceptive information to the brain, as the degree to which early injury modulates synaptic integration and membrane excitability in mature spinal projection neurons remains unclear. Here we demonstrate that neonatal surgical injury leads to a significant shift in the balance between synaptic excitation and inhibition onto identified lamina I projection neurons of the adult mouse spinal cord. The strength of direct primary afferent input to mature spinoparabrachial neurons was enhanced following neonatal tissue damage, whereas the efficacy of both GABAergic and glycinergic inhibition onto the same population was compromised. This was accompanied by reorganization in the pattern of sensory input to adult projection neurons, which included a greater prevalence of monosynaptic input from low-threshold A-fibers when preceded by early tissue damage. In addition, neonatal incision resulted in greater primary afferent-evoked action potential discharge in mature projection neurons. Overall, these results demonstrate that tissue damage during early life causes a long-term increase in the gain of spinal nociceptive circuits, and suggest that the prolonged consequences of neonatal trauma may not be restricted to the spinal cord but rather include excessive ascending signaling to supraspinal pain centers.
\end{abstract}

Key words: action potential; dorsal horn; injury; patch-clamp; spinal cord; synapse

\section{Introduction}

Painful experiences during childhood have been linked to a greater predisposition for developing chronic pain as adults (Walker et al., 2010, 2012). Tissue damage during early life, which commonly occurs as a consequence of neonatal intensive care treatment (Stevens et al., 2003; Carbajal et al., 2008), evokes longterm increases in pain sensitivity in children during prolonged noxious stimulation (Hermann et al., 2006; Wollgarten-Hadamek et al., 2009; Dengler-Crish et al., 2011). Neonatal injury leads to a localized "priming" of spinal nociceptive withdrawal reflexes in the mature rat, which manifests as an exacerbated mechanical and thermal hypersensitivity upon reinjury (Ren et al., 2004; Chu et al., 2007; Walker et al., 2009). This primed state arises from changes occurring within the dorsal horn of the spinal cord rather than at the peripheral site of injury (Beggs et al., 2012). The enhanced vulnerability to repeat injury is only observed if the initial injury occurs during the first postnatal week (Ren et al., 2004; LaPrairie and Murphy, 2007). Therefore, knowledge of how neonatal tissue injury influences the functional organization of mature nociceptive circuits will advance our mechanistic under-

Received Aug. 26, 2014; revised Dec. 15, 2014; accepted Dec. 19, 2014.

Author contributions: J.L., E.K., and M.L.B. designed research; J.L., E.K., and P.E.C. performed research; J.L., E.K., P.E.C., and M.L.B. analyzed data; J.L., E.K., and M.L.B. wrote the paper.

This work was supported by the National Institutes of Health (NS080889 to M.L.B.).

The authors declare no competing financial interests.

Correspondence should be addressed to Dr Mark L. Baccei, Pain Research Center, Department of Anesthesiology, University of Cincinnati Medical Center, 231 Albert Sabin Way, Cincinnati, 0 H 45267. E-mail: mark.baccei@uc.edu. DOI:10.1523/JNEUROSCI.3585-14.2015

Copyright $\odot 2015$ the authors $\quad 0270-6474 / 15 / 352438-14 \$ 15.00 / 0$ standing of the potential link between pediatric and adult chronic pain.

Recent work has investigated the long-term consequences of neonatal insults on neuronal processing within the spinal superficial dorsal horn (SDH). Adult dorsal horn neurons demonstrate greater excitability in vivo when preceded by neonatal tissue damage (Peng et al., 2003; Torsney and Fitzgerald, 2003), which could reflect prolonged deficits in glycinergic inhibition within lamina II following early surgical injury (Li et al., 2013). This would predict that neonatal injury increases the overall excitability, and therefore output, of adult spinal nociceptive circuits. However, these prior studies cannot comment directly upon the effects of early injury on the known output neurons of the SDH network, which convey noxious sensory information to the brain. These output neurons correspond to a small population of lamina I neurons ( 5\%; Spike et al., 2003) that are unlikely to be included in a general sampling of dorsal horn cells.

Given the critical importance of lamina I projection neurons for the generation of neuropathic and inflammatory pain (Mantyh et al., 1997; Nichols et al., 1999), it is essential to elucidate how early tissue damage modulates synaptic input to this specific population during adulthood. If the changes described above ultimately fail to significantly alter synaptic integration and membrane excitability in ascending projection neurons, it is not clear how such changes can be relevant for pain sensitivity. Unfortunately, nothing is currently known about how neonatal injury influences the pattern and strength of synaptic connections onto mature lamina I projection neurons.

Here we demonstrate that early surgical injury evokes longterm changes in excitatory and inhibitory synaptic signaling onto 

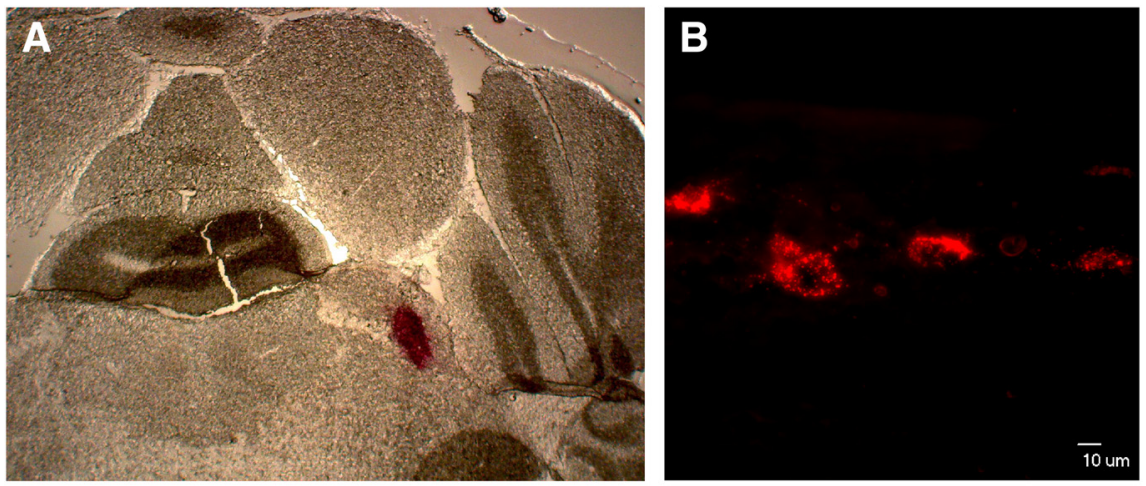

C

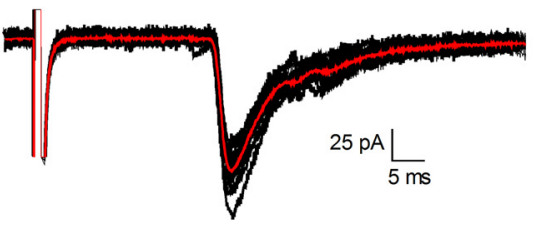

D

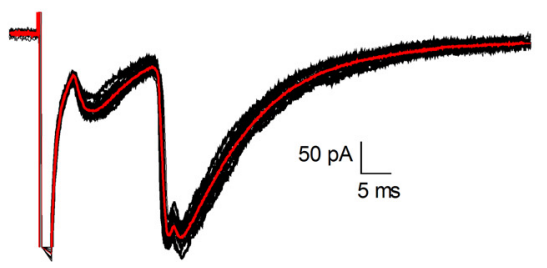

E

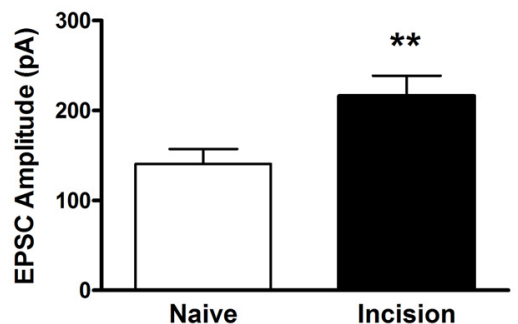

$\mathbf{F}$

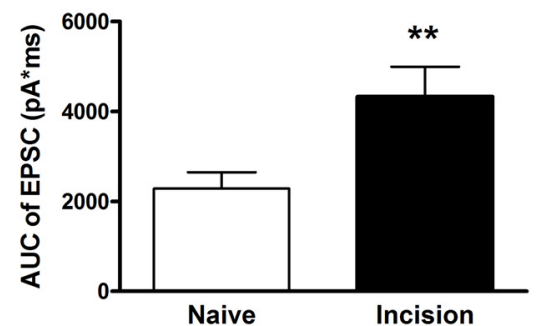

Figure 1. Neonatal surgical injury increases the efficacy of primary afferent synapses onto adult mouse lamina I projection neurons. $\boldsymbol{A}$, Coronal section of adult mouse brain illustrating the site of unilateral Dil injection into the parabrachial nucleus. $\boldsymbol{B}$ Sagittal section of the adult spinal cord showing fluorescently back-labeled spino-parabrachial neurons within lamina I. Scale bar, $10 \mu \mathrm{m}$. C, Examples of monosynaptic EPSC in a mature projection neuron evoked by dorsal root stimulation (average trace shown in red). D, Representative multiphasic EPSCs evoked by DR stimulation, suggesting that the sampled projection neuron received input from multiple subtypes of primary afferents. $\boldsymbol{E}$, Hindpaw incision at P3 significantly increased the amplitude of monosynaptic primary afferent-evoked EPSC in adult ( $8-10$ week) lamina I projection neurons ( ${ }^{* *} p=0.005$; Mann-Whitney test). F, P3 injury also led to a significantly greater area under the primary afferent-evoked EPSCs compared with naive littermate controls $\left({ }^{* *} p=\right.$ 0.002; Mann-Whitney test).

adult lamina I projection neurons, which exhibit enhanced action potential discharge in response to sensory input. We propose that this altered synaptic integration may significantly shift the input-output relationship of the adult spinal nociceptive network and thereby favor the amplification of ascending pain signals in the CNS.

\section{Materials and Methods}

All experiments adhered to animal welfare guidelines established by the University of Cincinnati Institutional Animal Care and Use Committee.

Neonatal surgical injury. At postnatal day (P)3, female mice [FVB$\operatorname{Tg}($ GadGFP) 4570Swn; Jackson Laboratories] were anesthetized with isoflurane (2-3\%) and a small incision made through the skin and underlying muscle of the plantar hindpaw as described previously (Brennan et al., 1996). The skin was immediately closed with 7-0 suture (Ethicon) and the wound fully healed in $\leq 2$ weeks. Littermate-matched controls, which were handled in an identical manner (including exposure to anesthesia) but did not receive hindpaw incision, were used for all experiments.

Identification of ascending spinal projection neurons. Approximately 1 week before euthanasia, adult mice $(18-22 \mathrm{~g})$ were anesthetized with a mixture of ketamine $(90 \mathrm{mg} / \mathrm{kg})$ and xylazine $(10 \mathrm{mg} / \mathrm{kg})$ and secured in a stereotaxic apparatus. For patch-clamp recordings, a single injection $(100-150 \mathrm{nl})$ of FAST DiI oil $(2.5 \mathrm{mg} / \mathrm{ml})$ was administered into the parabrachial nucleus (PB) using a Hamilton microsyringe (62RN; $2.5 \mu$ lvolume) equipped with a 28 gauge needle. Based on an atlas by Paxinos and Franklin (2012), the following stereotaxic coordinates were used (in $\mathrm{mm}$; relative to bregma): 4.8-5.0 caudal, 1.21.4 lateral and 4.0-4.2 ventral. For experiments involving the immunohistochemical analysis of synaptic inputs to lamina I projection neurons, $50-75 \mathrm{nl}$ of cholera toxin subunit B (CTB; 1\%; Sigma-Aldrich) was injected into the $\mathrm{PB}$ using the above approach.

In vitro spinal cord slice preparation. At P56P70, mice were deeply anesthetized with sodium pentobarbital $(60 \mathrm{mg} / \mathrm{kg})$ and perfused with ice-cold dissection solution consisting of the following (in mM): 250 sucrose, $2.5 \mathrm{KCl}, 25$ $\mathrm{NaHCO}_{3}, 1.0 \mathrm{NaH}_{2} \mathrm{PO}_{4}, 6 \mathrm{MgCl}_{2}, 0.5 \mathrm{CaCl}_{2}$, and 25 glucose continuously bubbled with $95 \%$ $\mathrm{O}_{2} / 5 \% \mathrm{CO}_{2}$. The lumbar spinal cord was isolated and immersed in low-melting-point agarose $\left(3 \%\right.$ in above solution) at $37^{\circ} \mathrm{C}$, which was then cooled on ice. Parasagittal slices (350-400 $\mu \mathrm{m})$ with the L4-L5 dorsal roots attached (length 7-10 mm) were cut from the side ipsilateral to the injury using a vibrating microtome (7000smz-2; Campden Instruments). Slices were incubated for 15-20 $\mathrm{min}$ in a recovery solution containing the following (in $\mathrm{mm}$ ): 92 NMDG, $2.5 \mathrm{KCl}, 1.2 \mathrm{NaH}_{2} \mathrm{PO}_{4}, 30$ $\mathrm{NaHCO}_{3}, 20$ HEPES, 25 glucose, $5 \mathrm{Na}$ ascorbate, 2 thiourea, $3 \mathrm{Na}$ pyruvate, $10 \mathrm{MgSO}_{4}$, and $0.5 \mathrm{CaCl}_{2}$ (Ting et al., 2011), and then allowed to recover further in an oxygenated artificial CSF (aCSF) solution containing the following (in mM): $125 \mathrm{NaCl}, 2.5 \mathrm{KCl}, 25 \mathrm{NaHCO}_{3}, 1.0$ $\mathrm{NaH}_{2} \mathrm{PO}_{4}, 1.0 \mathrm{MgCl}_{2}, 2.0 \mathrm{CaCl}_{2}$, and 25 glucose for $\geq 1 \mathrm{~h}$ at room temperature.

Patch-clamp recordings from identified lamina I projection neurons. After recovery, slices were transferred to a submersion-type recording chamber (RC-22; Warner Instruments) and mounted on the stage of an upright microscope (BX51WI, Olympus) which was equipped with fluorescence to allow for the identification of DiI-labeled neurons. Slices were then perfused at room temperature with oxygenated aCSF at a rate of $3-6 \mathrm{ml} / \mathrm{min}$.

Patch electrodes were constructed from thin-walled single-filamented borosilicate glass ( $1.5 \mathrm{~mm}$ outer diameter; World Precision Instruments) using a microelectrode puller (P-97; Sutter Instruments). Pipette resistances ranged from 4 to $6 \mathrm{M} \Omega$ and seal resistances were $>1 \mathrm{G} \Omega$. For recording action potential activity or EPSCs, electrodes were filled with an intracellular solution containing the following (in $\mathrm{mm}$ ): 130 K-gluconate, $10 \mathrm{KCl}, 10 \mathrm{HEPES}, 10 \mathrm{Na}$-phosphocreatine, $4 \mathrm{MgATP}$, and $0.3 \mathrm{Na}_{2}$-GTP, pH 7.2 (295-300 mOsm; calculated $\left.E_{\mathrm{Cl}}=-65.3 \mathrm{mV}\right)$. IPSCs (IPSCs) were recorded using an intracellular solution containing the following (in mM): 130 Cs-gluconate, $10 \mathrm{CsCl}, 10 \mathrm{HEPES}, 11 \mathrm{EGTA}$, 1.0 $\mathrm{CaCl}_{2}$, and 2.0 MgATP, pH 7.2 (295-300 mOsm).

Patch-clamp recordings were obtained from DiI-labeled neurons in lamina I (Ikeda et al., 2003; Li and Baccei, 2012) using a Multiclamp 700B amplifier (Molecular Devices). EPSCs were evoked from a holding potential of $-70 \mathrm{mV}$ by electrical stimulation of the dorsal $\operatorname{root}(10 \mu \mathrm{A}-1$ $\mathrm{mA}, 100 \mu \mathrm{s})$ delivered via a suction electrode connected to a constantcurrent stimulator (Master-8). The threshold to evoke an EPSC was defined as the current intensity that evoked a measurable EPSC in $\geq 50 \%$ of the trials. The stimulus threshold and onset latency of an evoked EPSC 
were jointly used to classify the observed synaptic response as mediated by low-threshold A-fibers, high-threshold A-fibers, lowthreshold C-fibers, or high-threshold C-fibers. It should be noted that using the EPSC latency and dorsal root (DR) length to calculate the conduction velocity $(\mathrm{CV})$ of the relevant primary afferent significantly underestimates the actual CV because this does not account for the following: (1) the unknown distance traveled by the afferent fiber upon penetrating the spinal cord. In this regard, it should be noted that in our parasagittal slice preparation, some EPSCs were recorded in projection neurons close to the L4 DR entry zone in response to L5 DR stimulation, which would add at least several millimeters to the overall length of the afferent pathway; (2) the CV of myelinated primary afferents may be slower within the spinal cord compared with the periphery because myelinated axons can become unmyelinated as they enter the CNS (Carlstedt, 1977; Thomas et al., 1993), which would result in a slower onset of the evoked EPSC; (3) the time needed for an action potential to be generated after the onset of the electrical stimulus (i.e., "utilization time"), estimated to be $\sim 0.9 \mathrm{~ms}$ in adult mouse primary afferents (Ruscheweyh et al., 2007), which leads to a proportionately larger error with short-latency responses (Waddell et al., 1989); or (4) the time required for synaptic transmission to occur $(\sim 1 \mathrm{~ms}$; Yamashita, 1986; Pinto et al., 2008). EPSCs mediated by low-threshold A-fibers were classified as monosynaptic based on their ability to follow repetitive stimulation ( 5 stimuli at $1.2 \times$ threshold delivered at $10-20 \mathrm{~Hz}$ ) with a constant latency and absence of failures. Highthreshold A-fiber and C-fiber mediated EPSCs were considered monosynaptic if no failures were observed during 2 and $1 \mathrm{~Hz}$ stimulation, respectively (Torsney and MacDermott, 2006). For recording miniature EPSCs (mEPSCs), TTX was added to the aCSF at $500 \mathrm{~nm}$. The effect of bath applying the TRPM8 agonist WS-3 (200 $\mu \mathrm{M})$ or the TRPV1 agonist capsaicin $(1 \mu \mathrm{M})$ on mEPSC properties was examined to determine whether these functional subpopulations of primary afferents directly synapse onto adult lamina I projection neurons.

In other experiments, polysynaptic IPSCs were recorded from a holding potential of $0 \mathrm{mV}$ following high-threshold stimulation of the dorsal $\operatorname{root}(1 \mathrm{~mA}, 100 \mu \mathrm{s})$. To quantify the efficacy of GABAergic and glycinergic inhibition, electronic subtraction was used to isolate the gabazinesensitive and strychnine-sensitive components of the IPSC and the area under the curve (AUC) of each component was calculated. Currentclamp recordings of primary afferent-evoked action potential discharge were obtained at the resting membrane potential of the sampled neuron.

Membrane voltages were adjusted for liquid junction potentials (approximately $-14 \mathrm{mV}$ ) calculated using JPCalc software (P. Barry, University of New South Wales, Sydney, Australia; modified for Molecular Devices). Currents were filtered at $4-6 \mathrm{kHz}$ through a $-3 \mathrm{~dB}$, four-pole low-pass Bessel filter, digitally sampled at $20 \mathrm{kHz}$, and stored on a personal computer (ICT) using a commercially available data acquisition system (Digidata 1440A with pClamp 10.3 software; Molecular Devices).

Classification of primary afferent input using CAPs. At the completion of each experiment, the dorsal root was cut near the dorsal root entry zone (final length $=6-9 \mathrm{~mm}$ ) and inserted into a second suction electrode connected to the amplifier headstage. Compound action potentials (CAPs) were recorded in response to electrical stimulation of the distal portion of the dorsal root $(0-1 \mathrm{~mA}$ at $100 \mu$ s duration) at room
B

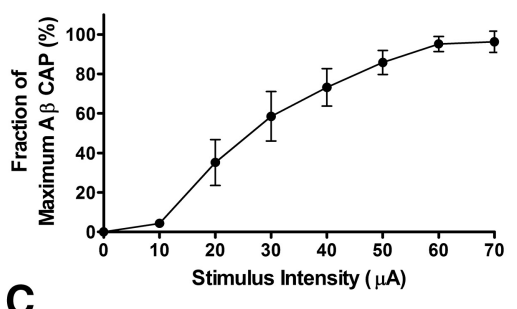

C

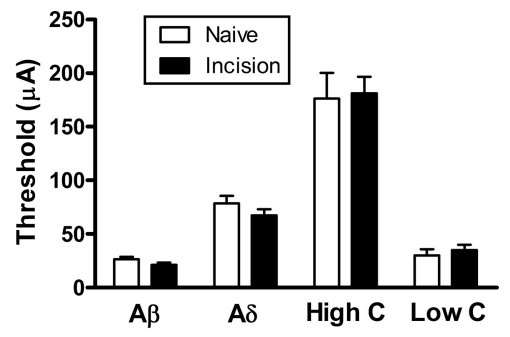

D

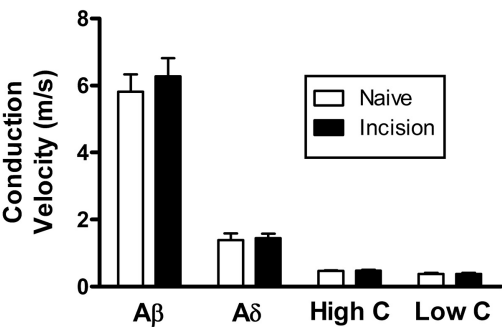

Figure 2. Early tissue damage does not alter the electrophysiological properties of primary afferent fibers in the adult dorsal root. A1-A3, Primary afferent input was classified via the recording of CAPs in the dorsal root in response to increasing stimulus intensity. Low

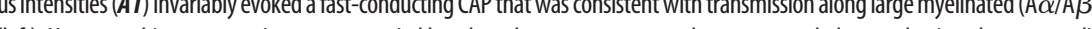
dorsal root. $\boldsymbol{B}$, Plot of the amplitude of the fastest conducting CAP (i.e., $A \alpha / A \beta$ fibers) as a function of stimulus intensity. $C, D$ mportantly, there were no significant long-term effects of neonatal tissue damage on the stimulus thresholds ( $p=0.629$; two-way ANOVA; $C$ or conduction velocities $(p=0.899 ; D)$ of any classes of primary afferent fibers.

A A f fiber
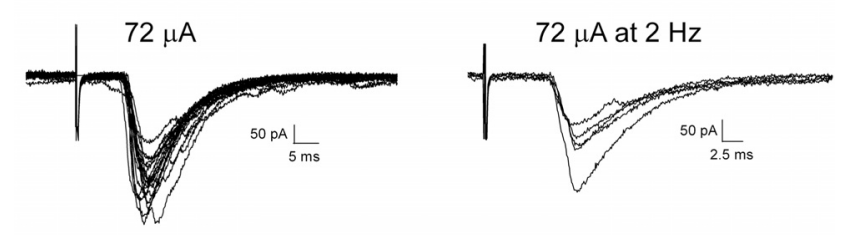

B High-threshold C-fiber
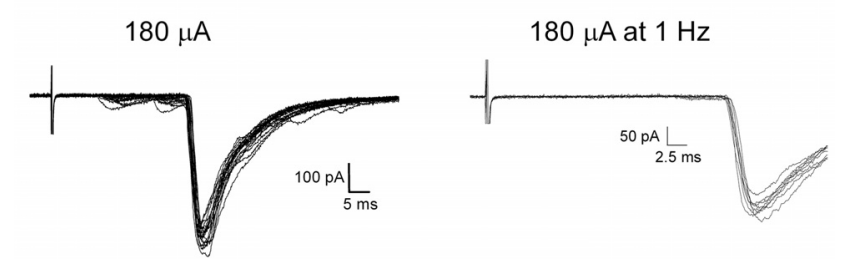

Figure 3. High-threshold primary afferent input to adult spino-parabrachial neurons. $A$, Representative example of EPSCs recorded in an adult lamina I projection neuron in response to primary afferent stimulation, with a threshold and onset latency that suggests mediation by high-threshold A $\delta$-fibers (left). The synaptic input was subsequently classified as monosynaptic based on its ability to follow repetitive stimulation with a stable latency and absence of failures (right). $\boldsymbol{B}$, Examples of EPSCS evoked by stimulation of high-threshold C-fibers (left), which was judged to be monosynaptic based on the ability to follow $1 \mathrm{~Hz}$ stimulation with an absence of failures (right). 
A Low-threshold (LT) A-fiber
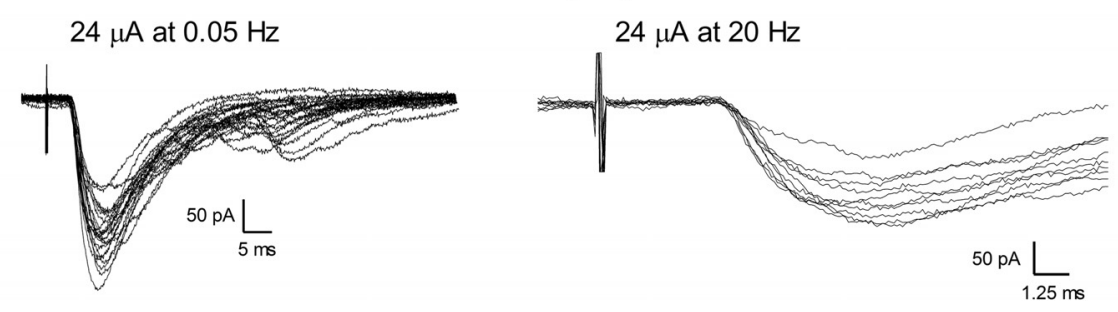

B

Low-threshold (LT) C-fiber

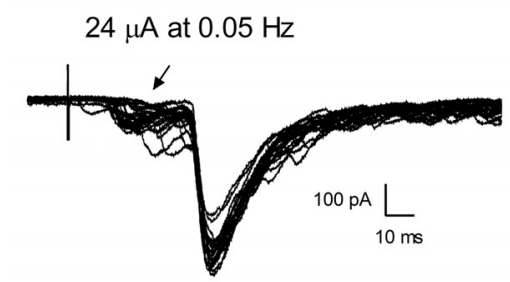

\section{$24 \mu \mathrm{A}$ at $1 \mathrm{~Hz}$}
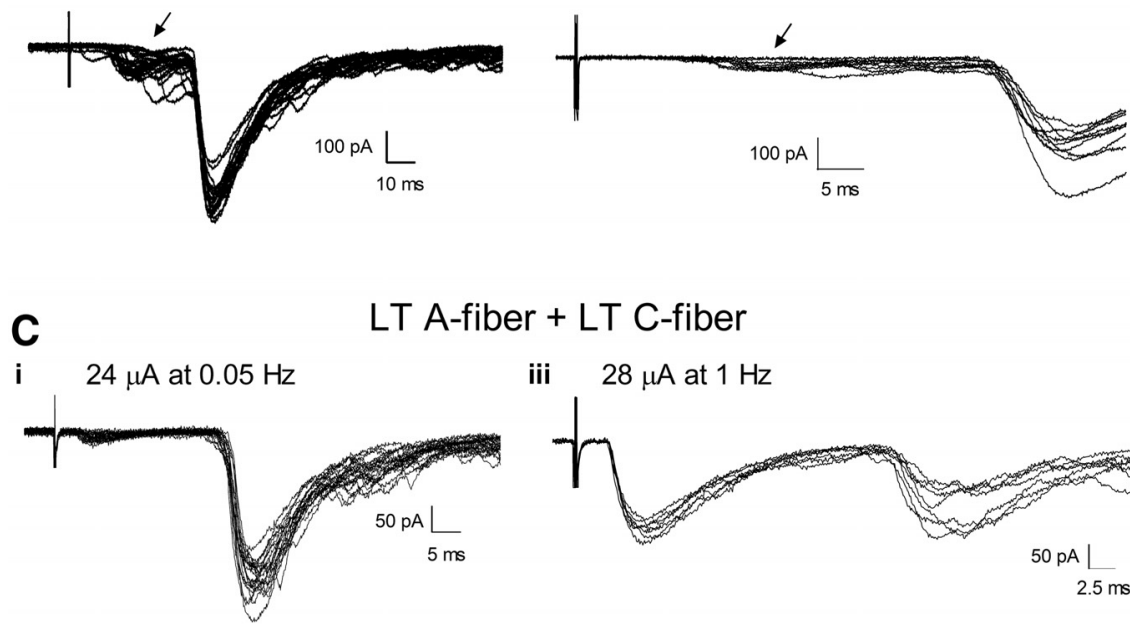

iii $28 \mu \mathrm{A}$ at $1 \mathrm{~Hz}$

ii $\quad 28 \mu \mathrm{A}$ at $0.05 \mathrm{~Hz}$

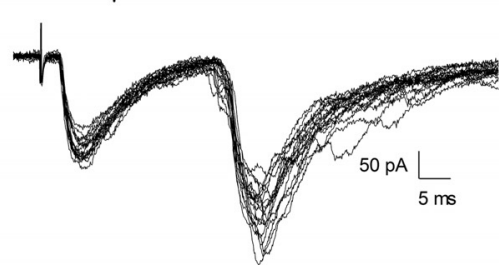

iv $\quad 28 \mu \mathrm{A}$ at $10 \mathrm{~Hz}$

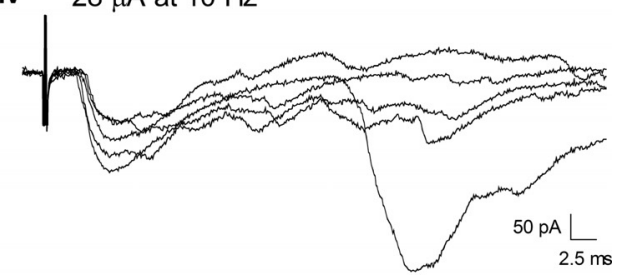

Figure 4. Adult lamina I projection neurons receive direct input from low-threshold sensory afferents in vitro. $\boldsymbol{A}$, Low-intensity electrical stimulation of the DR evoked a short latency EPSC in a mature spino-parabrachial neuron (left) that followed $20 \mathrm{~Hz}$ stimulation (right) and was thus classified as monosynaptic. $\boldsymbol{B}$, Example of a lamina I projection neuron that exhibited a longlatency EPSC in response to low-intensity DR stimulation (left) which followed $1 \mathrm{~Hz}$ stimulation (right), in contrast to a smaller EPSC with a shorter onset latency (arrow) which exhibited variable latencies and failures during tetanic stimulation and likely reflects polysynaptic input to the sampled neuron. Ci-Civ, Demonstration of a mature projection neuron receiving monosynaptic input from both low-threshold A-fibers and low-threshold C-fibers. Ci, Low-intensity DR stimulation evoked a long-latency EPSC that followed $1 \mathrm{~Hz}$ (Ciii). A slight increase in stimulus intensity recruited a second component that exhibited a short onset latency (Cii) and the ability to follow $10 \mathrm{~Hz}$ tetanic stimulation with a stable latency and absence of failures (Civ).

temperature. The stimulus intensities needed to activate $\mathrm{A} \alpha / \mathrm{A} \beta, \mathrm{A} \delta$, and C-fiber CAPs (see Fig. 2), and the measured conduction velocities, were used to classify the monosynaptic primary afferent-evoked EPSCs recorded earlier. This daily calibration of the stimulus parameters allowed us to account for animal-to-animal variability in the diameter of the attached dorsal roots and/or variability in the diameter of different stimulating electrodes.

Immunohistochemistry. Adult mice $(n=35)$ were killed by intraperitoneal injection of sodium pentobarbital (Fatal-Plus; Vortec Pharmaceuticals) and transcardially perfused with cold $0.1 \mathrm{M}$ phosphate buffer followed by $4 \%$ paraformaldehyde in phosphate buffer. Spinal cord lumbar enlargements were collected, postfixed overnight in $4 \%$ paraformaldehyde in phosphate buffer, and then transferred to $30 \%$ sucrose in phosphate buffer overnight or until the spinal cord sank. Cords were embedded in Tissue Freezing Medium (General Data) and rapidly frozen in a bath of isopentane cooled by dry ice. Horizontal or transverse sections $(60 \mu \mathrm{m})$ were cut on a Leica $1850 \mathrm{CM}$ cryostat and collected in $0.01 \mathrm{~m}$ PBS.

Free-floating sections were washed with PBS then permeabilized at room temperature (RT) for $1 \mathrm{~h}$ with PBS $+0.3 \%$ Triton X-100 (PBS$\mathrm{Tx})$, then blocked for 2-3 h at RT with $10 \%$ normal donkey serum (NDS; D9663; SigmaAldrich) and 1\% BSA in PBS-Tx. In sections to be stained with PSD-95 antibody, tissue underwent pepsin-mediated antigen retrieval (Watanabe et al., 1998; Polgár et al., 2008) before the permeabilization step. Tissue sections were incubated for $30 \mathrm{~min}$ at $37^{\circ} \mathrm{C}$ in PBS, followed by $30 \mathrm{~min}$ in $0.2 \mathrm{M} \mathrm{HCl}$ and $1 \mathrm{mg} / \mathrm{ml}$ pepsin (Fisher Scientific), then permeabilized and blocked as described above. Sections were incubated for 3 nights at $4^{\circ} \mathrm{C}$ in a mixture of primary antibodies against Cholera toxin subunit B (List Biological Catalog \#703, RRID: AB_10013220; 1:5000) and either VGLUT3 (EMD Millipore Catalog \#AB5421, RRID: AB_2187832; 1:8000), VGLUT1 (EMD Millipore Catalog \#AB5905, RRID:AB_2301751; 1:3000), GlyT2 (EMD Millipore Catalog \#AB1773, RRID:AB_90953; 1:4000), PSD-95 (Abcam Catalog \#ab18258, RRID:AB_444362; 1:200), or VGAT (Synaptic Systems GmbH Catalog \#131 002, RRID:AB_88787; 1:2500) in antibody buffer of $5 \%$ NDS and $1 \%$ BSA in PBS-Tx. Sections were washed $3 \times 30 \mathrm{~min}$ at RT in PBS-Tx then incubated overnight at $4^{\circ} \mathrm{C}$ with species-specific AlexaFluor-conjugated secondary antibodies (Life Technologies Catalog \#A11058, RRID:AB_10563390; Cata$\log$ \#A11073, RRID:AB_10562573; Catalog \#A11034, RRID:AB_10562715; 1:1000, Life Technologies Catalog \#A21447, RRID: AB_10584487, 1:500) in antibody buffer. Finally, sections were washed $3 \times 30 \mathrm{~min}$ at RT with PBS, mounted on Superfrost slides (Fisher Scientific), and coverslipped with Vectashield mounting medium (H-1400; Vector Laboratories).

Images were captured on a Zeiss LSM710 confocal microscope using either a $10 \times$ or $20 \times$ dry objective, or a $63 \times$ oil-immersion objective. For $z$-stack images, the interval between optical sections is $0.5 \mu \mathrm{m}$. Whenever multiple lines of the laser were used for the same image, scanning was done sequentially. The majority of image analysis was performed using Zeiss Image Browser, with Adobe Photoshop CS5 used to assemble figures.

Quantitation of GlyT2 or VGAT-immunoreactive contacts onto adult projection neurons. CTB-labeled lamina I projection neurons were selected from animals injected with CTB before euthanasia as described above. A maximum of three cells were selected from each mouse before observation of VGAT or GlyT2 immunostaining. For each neuron selected, a $z$-stack image series was taken spanning as much of the cell body and dendritic tree as possible under the $63 \times$ oil-immersion objective. The resulting $z$-series was analyzed using Photoshop CS5 (Adobe) to produce a drawing of the neuron and plot contacts from VGAT or GlyT2-immunoreactive axonal boutons using a technique described previously (Todd et al., 2002). The number of either VGAT or GlyT2 contacts per $1000 \mu \mathrm{m}^{2}$ of combined somatic and dendritic surface area was determined for each neuron as follows: dendrites were assumed to be cylindrical, and the cell body was assumed to be an ellipsoid having the following surface area: 


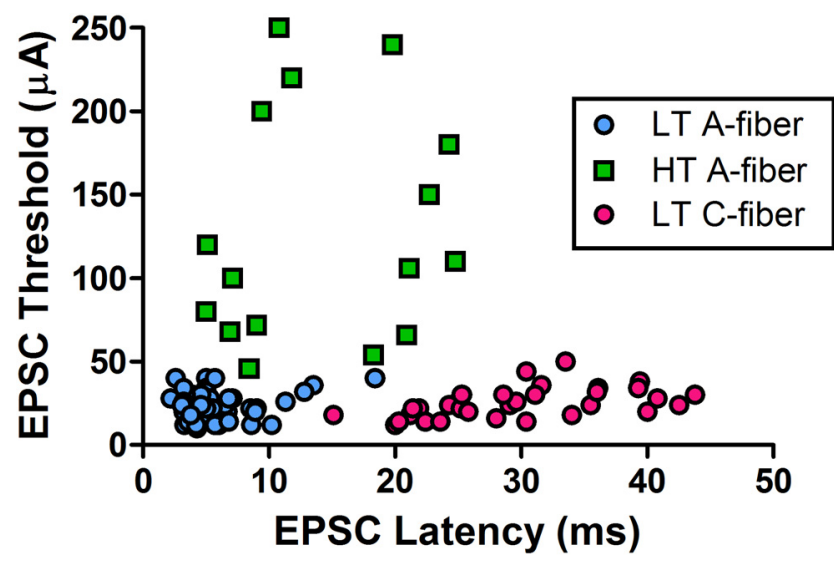

Figure 5. In vitro classification of monosynaptic primary afferent inputs to adult lamina I projection neurons. EPSCs evoked by dorsal root stimulation that met the criteria for a monosynaptic response (see Materials and Methods) were classified as being mediated by LT A-fibers (blue), HT A-fibers (green), LT C-fibers (pink), or HT C-fibers (data not shown). Each symbol represents a single lamina I projection neuron. A combination of EPSC threshold and EPSC latency (corrected for synaptic delay) was considered to categorize the subtype of primary afferent input to the sampled projection neuron. The stimulus thresholds and axonal conduction velocities used to classify the afferent subtype were calibrated on a daily basis following the recordings of CAPs from the dorsal roots as described earlier. Low-threshold A-fiber inputs could be distinguished from HT A-fiber inputs based on both stimulus intensity and EPSC onset latency, and separated from the low-threshold C-fiber responses based on EPSC latency alone.

$$
S=4 \pi\left(\frac{(a b)^{1.6}+(a c)^{1.6}+(b c)^{1.6}}{3}\right)^{1 / 1.6}
$$

where $a$ is the length of the soma at longest point, $b$ is the width at widest point, and $c$ is the depth of the $z$-series image for each cell. All measurements were obtained in LSM Image Browser (Zeiss) using the line drawing tool or open free shape curve tool.

Data analysis and statistics. Electrophysiological data were analyzed using Clampfit (Molecular Devices) or Mini Analysis (v6.0.3; Synaptosoft) software. Nonparametric statistical tests (Mann-Whitney or Wilcoxon signed rank tests for two groups; Prism 5.0, GraphPad Software) were used in any cases in which the distribution of data failed the D'Agostino and Pearson normality test (Prism). $\chi^{2}$ tests were used to compare the patterns of primary afferent input between the naive and neonatally incised groups. $n$ refers to the number of neurons sampled in a given group unless specified otherwise. Data are expressed as means \pm SEM.

\section{Results}

Neonatal surgical injury strengthens direct sensory input to adult lamina I projection neurons

Primary afferent-evoked EPSCs were recorded in identified spino-parabrachial neurons within lamina I of the adult mouse spinal cord (Fig. 1A,B). Mature projection neurons exhibited either monophasic (Fig. 1C) or multiphasic EPSCs (Fig. 1D), which were classified as monosynaptic based on their ability to follow repetitive stimulation (see Materials and Methods). The majority of sampled projection neurons also demonstrated polysynaptic EPSCs following DR stimulation (data not shown). Hindpaw incision at P3 significantly enhanced the efficacy of monosynaptic primary afferent input to adult lamina I projection neurons, as evidenced by a significantly greater peak EPSC amplitude in neonatally incised mice compared with naive littermate controls (Naive, $n=42$; P3 Incision, $n=41 ; p=0.005$; Mann-Whitney test; Fig. 1E). Given that peak EPSC amplitude may not always be an optimal measure of the global excitatory input to neurons that receive either multiphasic monosynaptic EPSCs (Fig. 1D) or a combination of monosynaptic and polysyn- aptic EPSCs (data not shown), the integrated area under the EPSC was also measured as an indicator of overall glutamatergic drive onto lamina I projection neurons. Importantly, neonatal incision significantly increased the area under the primary afferent-evoked EPSCs compared with naive littermate controls $(p=0.002$; Mann-Whitney test; Fig. $1 F)$.

\section{Adult lamina I projection neurons receive monosynaptic input from both low-threshold and high-threshold sensory afferents in vitro}

To classify the functional subtypes of primary afferents (i.e., Aand C-fibers) which synapse onto ascending projection neurons in the adult mouse spinal cord, at the end of each experiment, CAPs were recorded from the proximal portion of the L4/L5 DRs in response to distal electrical stimulation at increasing intensities. In the vast majority of DR examined, increasing the stimulus intensity between 10 and $40 \mu \mathrm{A}$ enhanced the amplitude of the fastest conducting (i.e., $\mathrm{A} \alpha / \mathrm{A} \beta$ ) $\mathrm{CAP}$ (Fig. $2 B$ ) without evidence of an $\mathrm{A} \delta$-mediated CAP, although it is possible that a lowthreshold $\mathrm{A} \delta$ component is masked by the $\mathrm{A} \alpha / \mathrm{A} \beta$ wave. Interestingly, in some DR, these low intensity stimuli $(10-40 \mu \mathrm{A})$ could nonetheless evoke two distinct CAPs: one possessing a fast $\mathrm{CV}$ in the $\mathrm{A} \alpha / \mathrm{A} \beta$ range $(3.5-11.7 \mathrm{~m} / \mathrm{s})$ and a much slower component with an estimated $\mathrm{CV}$ of $<0.4 \mathrm{~m} / \mathrm{s}$ (Fig. $2 A 1, D$ ) that was accordingly categorized as a low-threshold C-fiber response. Although the mean $\mathrm{CV}$ of the $\mathrm{A} \alpha / \mathrm{A} \beta$-mediated CAP is lower than previously reported for mouse cutaneous afferents at $32^{\circ} \mathrm{C}$ (Koltzenburg et al., 1997), this would be expected as our recordings were obtained at room temperature $\left(21-22^{\circ} \mathrm{C}\right)$ and the $\mathrm{CV}$ in rodent primary afferents can be reduced by $>1 \mathrm{~m} / \mathrm{s}$ per ${ }^{\circ} \mathrm{C}$ (Birren and Wall, 1956). In addition, our calculated CV does not consider the utilization time (see Materials and Methods), which produces a proportionately larger underestimation of CV with shorter nerve segments (Waddell et al., 1989; Ruscheweyh et al., 2007). A progressive increase in the stimulus intensity recruited additional components of the CAP which were classified as being mediated by high-threshold A $\delta$-fibers (CV range: $0.7-3.0 \mathrm{~m} / \mathrm{s}$; Fig. $2 A 2$ ) or high-threshold C-fibers (Fig. 2A3) based on their stimulus thresholds and CVs. Notably, there was no significant effect of P3 hindpaw injury on the mean electrical threshold (Naive, $n=14$; Incision, $n=15 ; p=0.629$; two-way ANOVA; Fig. $2 C$ ) or $\mathrm{CV}$ $(p=0.899$; two-way ANOVA; Fig. $2 D)$ of primary afferent fibers in the adult dorsal roots.

As expected, the majority of lamina I projection neurons in naive mice ( 24 of 35 cells; $\sim 69 \%$ ) received monosynaptic input from high-threshold A $\delta$ or C-fiber primary afferents (Fig. 3), as reported previously in the rat (Dahlhaus et al., 2005). Interestingly, we also observed the presence of EPSCs with short onset latencies ( $n=6$; Fig. $4 A$, left) that were recruited at stimulus intensities $(10-40 \mu \mathrm{A})$ that selectively activated low-threshold (LT) A-fiber afferents in subsequent CAP recordings from the same dorsal root. It should be noted that while the recordings of CAPs from each dorsal root aided in the daily calibration of the stimulus parameters needed to activate different classes of primary afferents, the afferent inputs that correspond to the $\mathrm{A} \beta / \mathrm{A} \delta$ transitional zone remain difficult to classify and thus we cannot exclude the possibility that some short-latency EPSCs are mediated by LT A $\delta$-fibers. As a result, putative LT A $\beta$-mediated and LT A $\delta$-mediated synaptic responses were grouped into a "LT A-fiber" category in the present study. These low-threshold A-fiber responses could be classified as monosynaptic due to their ability to follow $10-20 \mathrm{~Hz}$ stimulation with a fixed latency and without the presence of failures (Fig. $4 A$, right). In other 

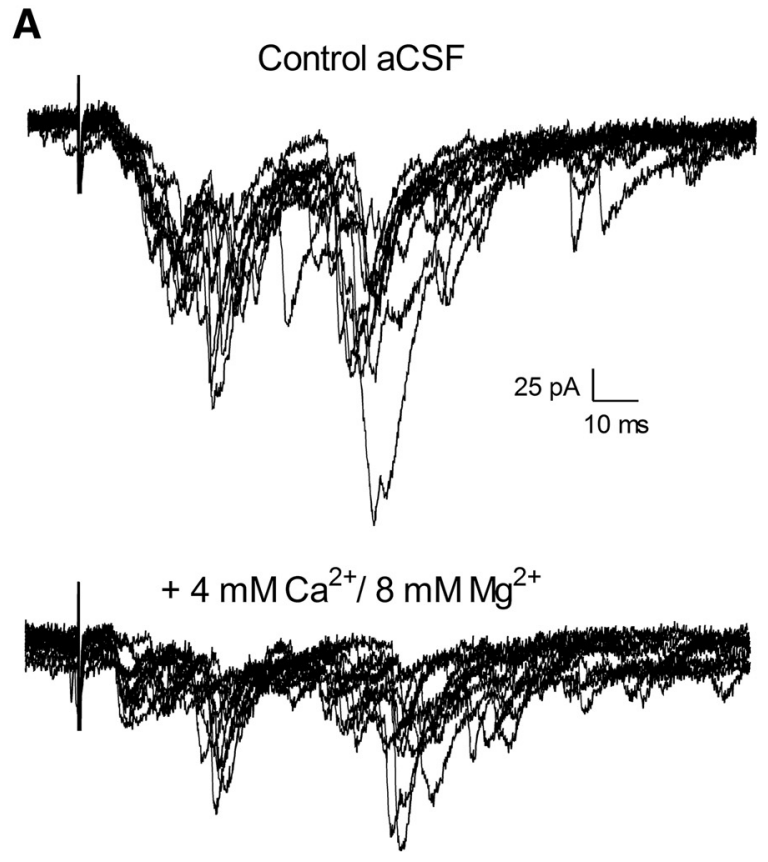

B
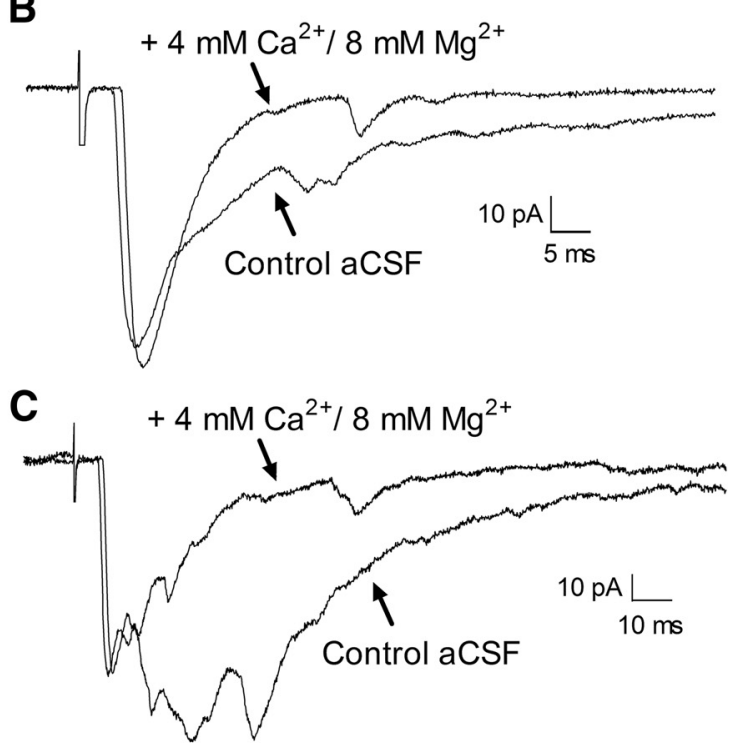

D

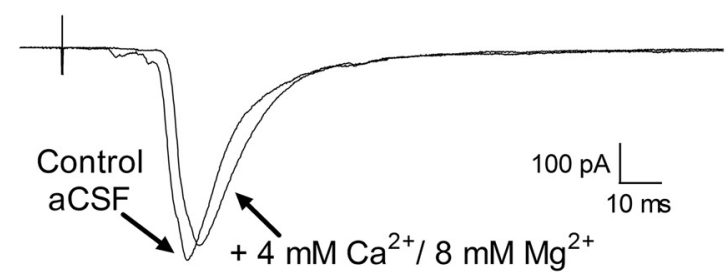

Figure 6. Effect of high external divalent cations on primary afferent-evoked EPSCs in adult lamina I projection neurons. $\boldsymbol{A}$, Top, Example of complex EPSCS that were evoked by primary afferent stimulation in the presence of normal aCSF. The EPSCS were classified as polysynaptic based on their variable onset latency and the presence of failures during repetitive stimulation (data not shown). Bottom, Bath application of an external solution containing $4 \mathrm{~mm} \mathrm{Ca}^{2+}$ and $8 \mathrm{~mm} \mathrm{Mg}^{2+}$ to suppress polysynaptic transmission significantly decreased the amplitude of these primary afferent-evoked EPSCS. B, C, Representative examples of EPSCs evoked in adult lamina I projection neurons that consisted of a short-latency component which was recruited at low-threshold A-fiber stimulus intensities $(B, 20 \mu \mathrm{A} ; \boldsymbol{C}, 30 \mu \mathrm{A})$ and followed high-frequency stimulation, in addition to longer-latency components. Perfusion with a high $\mathrm{Ca}^{2+} / \mathrm{Mg}^{2+}$ solution reduced the late phase of the EPSC without affecting the amplitude of the short-latency neurons $(n=5)$, low-intensity stimulation of the dorsal root evoked long-latency EPSCs that followed $1 \mathrm{~Hz}$ stimulation without failures (Fig. 4B), suggesting the presence of monosynaptic connections between LT C-fiber afferents and lamina I projection neurons in the mature SDH. Figure $4 C$ illustrates an example of an adult projection neuron which received multiple subtypes of direct primary afferent input. Low-intensity stimulation (at 24 $\mu \mathrm{A}$ ) evoked a long-latency EPSC (Fig. 4Ci) which could follow 1 $\mathrm{Hz}$ stimulation (Fig. 4Ciii). Increasing the stimulus intensity to $28 \mu \mathrm{A}$ (later demonstrated with CAP recording to selectively activate LT A-fibers) recruited an additional EPSC that exhibited both a short latency (Fig. 4Cii) and the ability to follow $10 \mathrm{~Hz}$ stimulation (Fig. 4Civ). Based on our classification criteria (see Materials and Methods), a neuron with this pattern of evoked responses ( $n=1$ in naive mice) was judged to receive monosynaptic input from both LT A-fibers as well as LT C-fibers.

Figure 5 depicts the overall distribution of primary afferentevoked EPSCs (across all experiments) that were judged to be monosynaptic based on their responses to repetitive stimulation, plotted as a function of the EPSC threshold and EPSC onset latency. LT A-fiber inputs clustered at low stimulus thresholds $(\leq 40 \mu \mathrm{A})$ and short EPSC latencies (mean $=5.7 \pm 0.4 \mathrm{~ms} ; n=$ 52 ), and could thus be distinguished from LT C-fiber inputs which exhibited significantly longer onset latencies $(30.7 \pm 1.6$ ms; $n=33 ; p<0.001$; Kruskal-Wallis test with Dunn's multiplecomparison test) comparable with those shown by highthreshold (HT) C-fiber responses ( $28.1 \pm 1.4 \mathrm{~ms} ; n=32$; data not shown). Meanwhile, while the population of HT A-fiber evoked inputs showed some overlap with the LT A-fiber inputs in terms of EPSC latency (which could reflect differences in dorsal root length across different experiments), HT A-fiber mediated responses nonetheless had significantly longer latencies (14.1 \pm $1.8 \mathrm{~ms} ; n=16 ; p<0.05$ compared with LT A-fiber responses) in addition to their higher stimulus intensities (Fig. 5).

To further support the conclusion that low-threshold A-fibers and low-threshold C-fibers make monosynaptic connections onto adult mouse projection neurons, we also examined the effects of bath applying a solution containing high concentrations of divalent cations ( $4 \mathrm{mM} \mathrm{Ca}^{2+} / 8 \mathrm{mM} \mathrm{Mg}^{2+}$ ) on primary afferent-evoked EPSCs. Previous work has shown that high external $\mathrm{Ca}^{2+} / \mathrm{Mg}^{2+}$ predominantly blocks polysynaptic transmission in the CNS (Berry and Pentreath, 1976; Rose and Metherate, 2005; Shreckengost et al., 2010) via increasing the activation threshold of voltage-gated $\mathrm{Na}^{+}$channels, thereby making it more difficult for an intervening neuron within a polysynaptic pathway to reach action potential threshold. Figure $6 \mathrm{~A}$ (top) illustrates an example of a primary afferent-evoked EPSC that was previously classified as polysynaptic based on a variable onset latency and the presence of synaptic failures during repetitive stimulation (data not shown). As predicted by the earlier studies, the application of modified aCSF containing high $\mathrm{Ca}^{2+} / \mathrm{Mg}^{2+}$ considerably reduced this synaptic input to lamina I projection neurons (Fig. 6A,

$\leftarrow$

component, suggesting that this short-latency EPSC reflects a monosynaptic connection onto the projection neuron. A small delay in the EPSC latency (and the onset of the CAP in the dorsa root recordings; data not shown) was often observed, which may relate to the elevated firing threshold in the presence of high external divalents. D, Example of an EPSC evoked by the stimulation of low-threshold C-fibers (threshold $=20 \mu \mathrm{A}$ ) that was classified as monosynaptic based on its ability to follow repetitive stimulation (data not shown). Bath application of high $\mathrm{Ca}^{2+} / \mathrm{Mg}^{2+}$ had a minimal effect on the amplitude of the evoked EPSC, thus providing additional support of a direct connection between low-threshold C-fibers and mature projection neurons. 

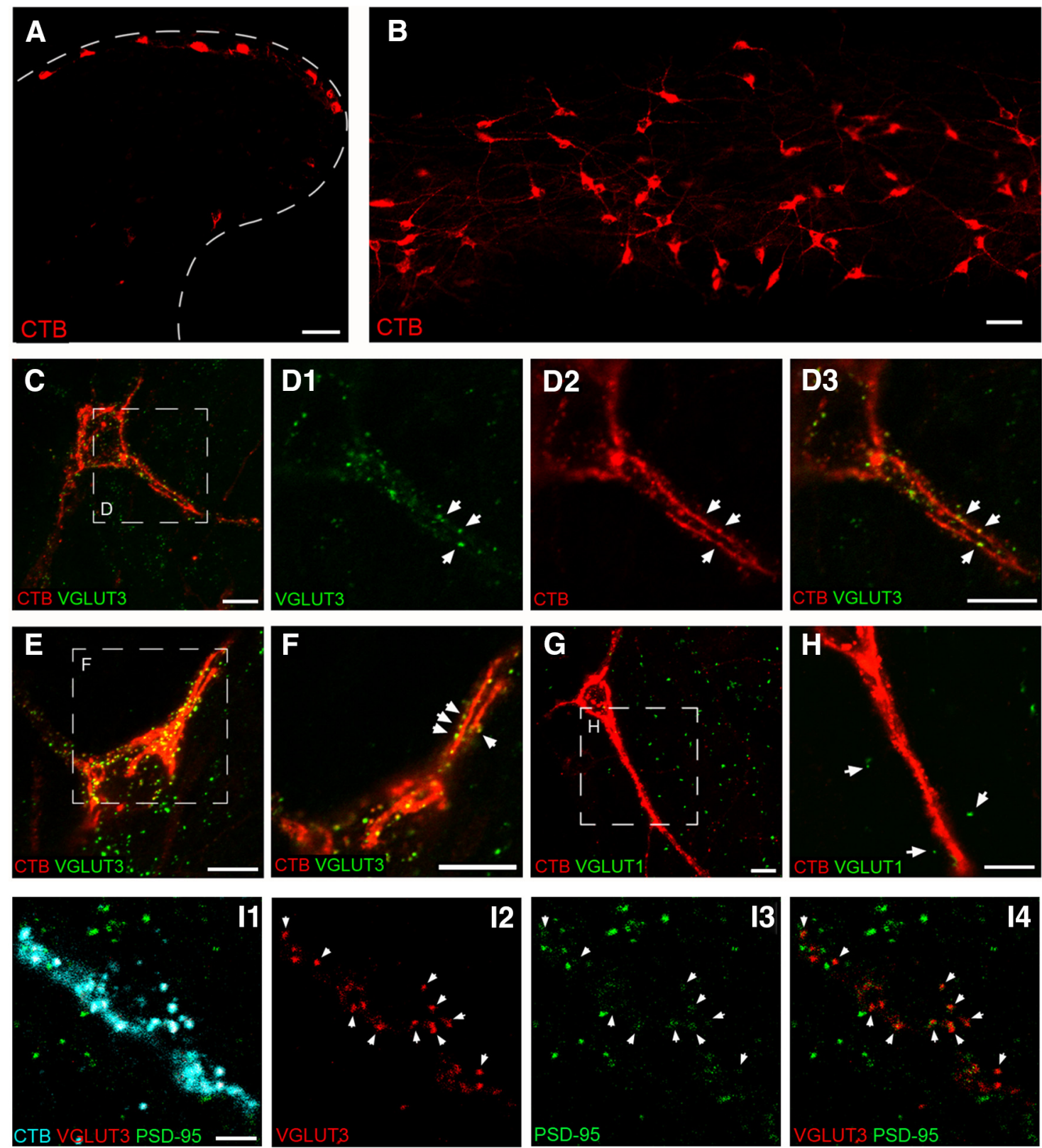

Figure 7. Adult lamina I projection neurons are innervated by VGLUT3-expressing axonal boutons. A, Transverse section of spinal cord illustrating lamina I neurons back-labeled via injections of CTB into the parabrachial nucleus. $\boldsymbol{B}$, Horizontal $(60 \mu \mathrm{m})$ section through the superficial dorsal horn demonstrating robust somatic and dendritic labeling of numerous ascending projection neurons. Scale bars: $A, B, 50 \mu \mathrm{m}$. C, D, Immunohistochemical localization of the vesicular glutamate transporter VGLUT3, a known marker for low-threshold C-fiber mechanoreceptors, revealed VGLUT3positive boutons (green) in close apposition (arrows) to the soma and dendrites of projection neurons identified by staining for CTB (red). C, Representative of a flattened projection of eight $z$-stack optical slices, whereas D1-D3 represents a single 0.5- $\mu \mathrm{m}$-thick optical section shown at a higher-magnification from the boxed region in $\boldsymbol{C}$. $\boldsymbol{E}$, Flattened projection of nine $z$-stack optical slices illustrating another representative projection neuron which received numerous putative synaptic contacts from VGLUT3-containing afferents. $F$, Single $0.5 \mu \mathrm{m}$ optical slice showing highermagnification of the boxed region in $\boldsymbol{E}$. $\boldsymbol{G}$, In contrast, lamina I projection neurons (red) were rarely contacted by axonal boutons expressing VGLUT1 (green), a marker of large myelinated fibers associated with innocuous mechanoreceptors. $\boldsymbol{H}$, Higher-magnification of the boxed region in $\mathbf{G}$, demonstrating a lack of VGLUT1-positive boutons (arrows) in the immediate vicinity of the adult projection neuron. Scale bars, $\mathbf{C}-\boldsymbol{H}, 10 \mu \mathrm{m}$. I, Single $0.5 \mu \mathrm{m}$ optical sections illustrating the soma and proximal dendrites of a fusiform projection neuron back-labeled with (TB (cyan; I1) which

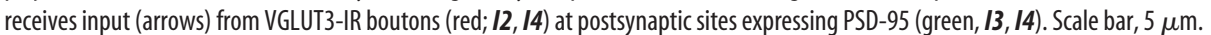

bottom). Importantly, when the response to repetitive stimulation suggested the presence of both monosynaptic and polysynaptic inputs mediated by LT A-fibers, the high $\mathrm{Ca}^{2+} / \mathrm{Mg}^{2+}$ solution selectively suppressed the long-latency components of the EPSC, whereas the short-latency component was relatively unaffected (Fig. $6 B, C$ ), which is consistent with a preferential dampening of polysynaptic transmission in the dorsal horn in the presence of elevated divalent cations. Similarly, Figure $6 D$ depicts an example of a low-threshold C fiber-mediated EPSC that was judged to be monosynaptic based on its ability to follow repetitive stimulation. Subsequent perfusion with high $\mathrm{Ca}^{2+} / \mathrm{Mg}^{2+}$ had a minimal effect on the amplitude of the evoked EPSC, providing further evidence that it was monosynaptic in nature.

To provide anatomical support for the existence of direct connections between LT C-fibers and lamina I projection neurons, we next investigated whether synaptic boutons exhibiting immunoreactivity (IR) for the vesicular glutamate transporter VGLUT3, a well established marker of LT C-fiber 
A
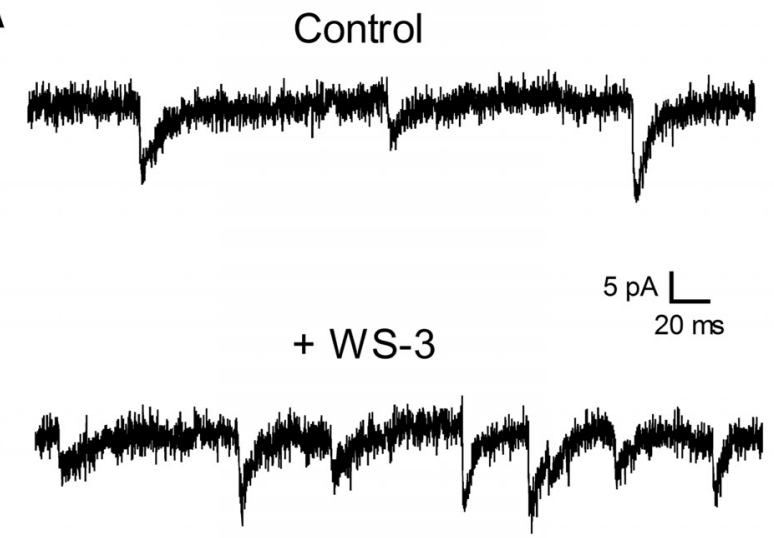

B

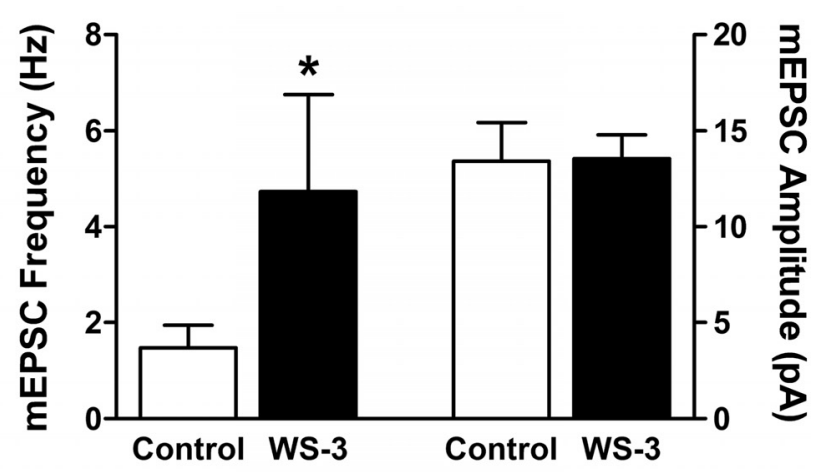

C

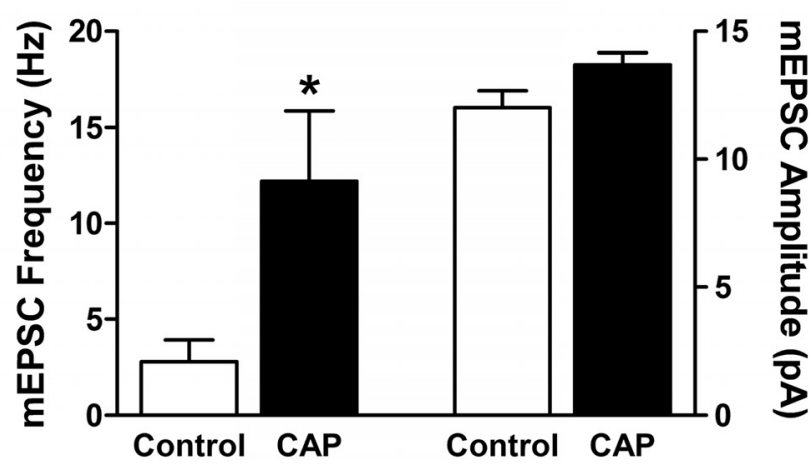

Figure 8. Adult lamina I projection neurons receive input from TRPM8- and TRPV1expressing synapses. $\boldsymbol{A}$, Representative traces showing $\mathrm{mEPSC}$ (recorded from a holding potential of $-70 \mathrm{mV}$ before (Control) and after the bath application of the selective TRPM 8 agonist WS-3. $\boldsymbol{B}$, The activation of TRPM8 resulted in a significant increase in the frequency ${ }^{*} p=$ 0.031; Wilcoxon signed rank test; left), but not amplitude ( $p=0.843$; right), of mEPSCs recorded in lamina I projection neurons from adult naive mice. C, Perfusion of the TRPV1 agonist capsaicin also significantly potentiated mEPSC frequency in mature projection neurons $\left({ }^{*} p=\right.$ 0.032; Mann-Whitney test; left).

neurons (Seal et al., 2009), make direct contacts with projection neurons identified via the retrograde transport of CTB from the brain (Fig. $7 A, B$ ). As illustrated in Figure $7 C-F$, numerous VGLUT3-IR terminals were observed in close apposition to the soma and dendrites of lamina I projection neurons. At least some of these VGLUT3-IR terminals likely correspond to synapses onto the projection neurons, as evidenced by colocalization with the postsynaptic marker PSD-95 (Fig. 7I). In contrast, mature projection neurons received sparse putative contacts from axonal boutons labeled with a primary antibody raised against VGLUT1
A

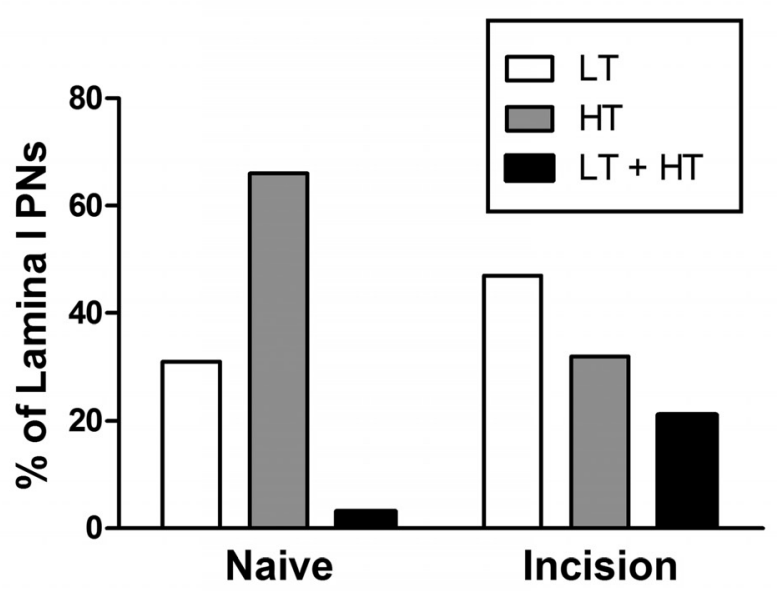

B

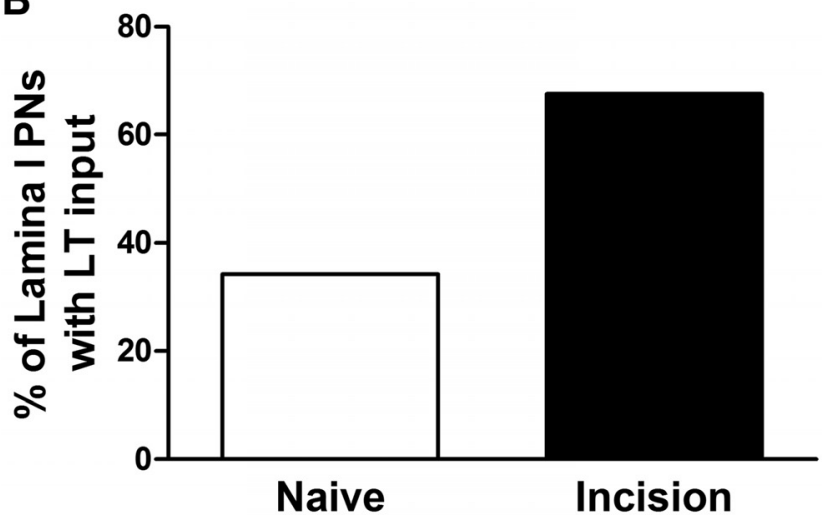

Figure 9. Early tissue damage alters the distribution of primary afferent inputs to adult spino-parabrachial neurons. $\boldsymbol{A}$, Plot showing the percentage of lamina I projection neurons (PNs) which received monosynaptic input from LT afferents, HT, or both (LT + HT), demonstrating an increased prevalence of $\mathrm{LT}$ and $\mathrm{LT}+\mathrm{HT}$ input following $\mathrm{P} 3$ hindpaw incision ( $p=$ $0.008 ; \chi^{2}$ test). $\boldsymbol{B}$, The percentage of adult projection neurons receiving monosynaptic lowthreshold input was significantly elevated by neonatal surgical injury $(p=0.008$; Fisher's exact test).

(Fig. 7G,H), which is thought to be predominantly expressed within innocuous $\mathrm{A} \beta$-fiber mechanoreceptors and/or proprioceptors within the DRG (Todd et al., 2003; Alvarez et al., 2004; Yasaka et al., 2014).

Given that an estimated 90\% of VGLUT3-positive C-fibers in the mouse express TRPM8 (Draxler et al., 2014) and that TRPM8 activation elevates glutamate release in the rodent superficial dorsal horn (Baccei et al., 2003; Draxler et al., 2014), if the above VGLUT3-IR terminals (Fig. 7) do represent functional synapses then the application of TRPM8 agonists should increase mEPSC frequency in adult lamina I projection neurons. Indeed, the bath application of WS-3 significantly elevated mEPSC frequency $(n=6 ; p=0.031$; Wilcoxon signed rank test; Fig. $8 A, B$, left $)$ without influencing mEPSC amplitude $(p=0.843$; Fig. $8 B$, right). As expected, mature projection neurons also received input from TRPV1-expressing afferents, as evidenced by the significant increase in mEPSC frequency in response to capsaicin (Fig. 8C).

Neonatal tissue damage alters the pattern of sensory input to mature spinal projection neurons

To facilitate the statistical comparison of the distribution of direct primary afferent inputs to lamina I projection neurons in 
A

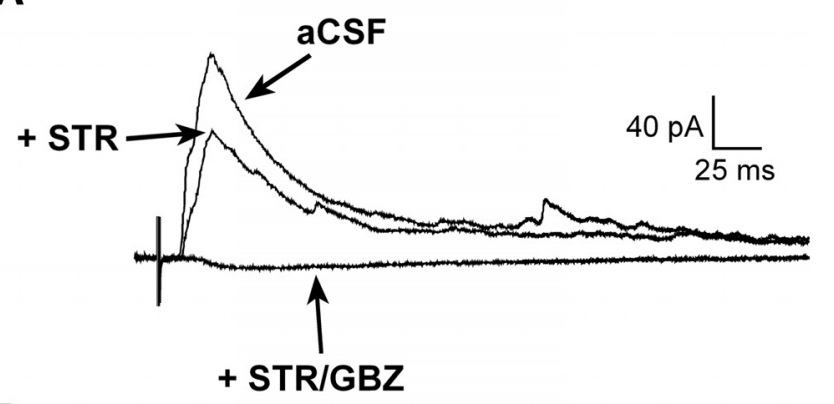

B

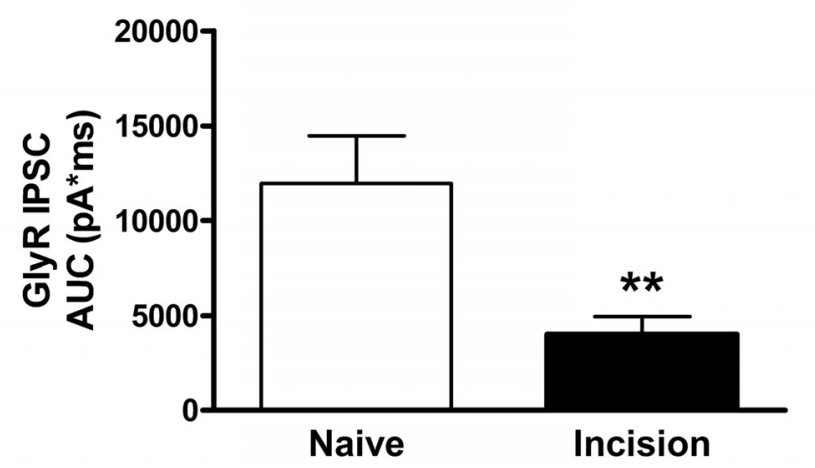

C

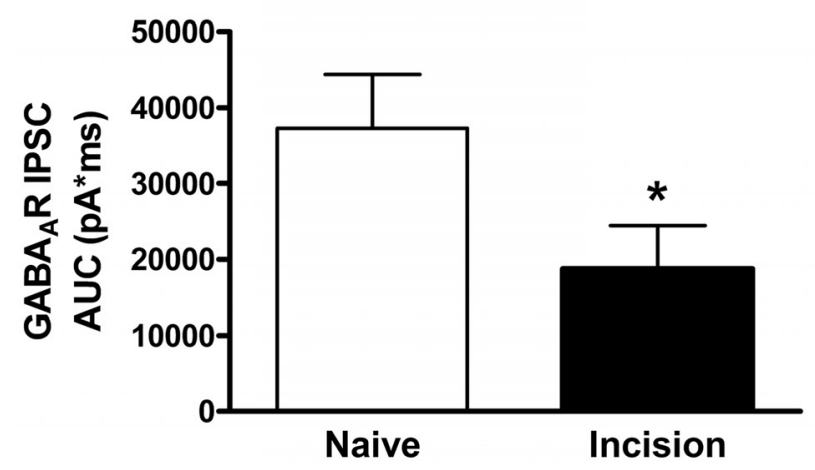

Figure 10. Deficits in feedforward inhibition of mature projection neurons following neonatal tissue injury. $\boldsymbol{A}$, Example of polysynaptic IPSCs recorded in an adult lamina I projection neuron in response to electrical stimulation of the dorsal root before (aCSF) and after the sequential bath application of the GlyR antagonist strychnine (STR; $0.5 \mu \mathrm{m}$ ) and the GABA $R$ antagonist gabazine (GBZ; $10 \mu \mathrm{M}) . \boldsymbol{B}, \mathbf{C}$, Hindpaw injury at $\mathrm{P} 3$ caused a significant reduction in the efficacy of both primary afferent-evoked glycinergic $\left({ }^{* *} p=0.005\right.$; Mann-Whitney test; $\boldsymbol{B})$ and GABAergic $\left({ }^{*} p=0.033 ; \boldsymbol{C}\right)$ transmission onto adult projection neurons, as measured by the area under the STR-sensitive and GBZ-sensitive IPSCS following electronic subtraction (AUC).

naive and neonatally incised mice during adulthood, monosynaptic EPSCs were classified as LT (consisting of LT A-fiber and LT C-fiber evoked responses) or HT (mediated by HT A $\delta$-fiber or HT C-fiber afferents). The pattern of primary afferent input to adult lamina I projection neurons was significantly changed by ipsilateral tissue injury during the early postnatal period (Naive: $n=35$; P3 Incision: $n=35 ; p=0.008 ; \chi^{2}$ test), with a decrease in the percentage of lamina I neurons which received monosynaptic input solely from HT afferents and a corresponding increase in the fraction of neurons that were innervated by either LT or a combination of LT and HT primary afferent fibers (Fig. 9A). As a result, the prevalence of lamina I spino-parabrachial neurons that received monosynaptic input from $\mathrm{LT}$ afferents was significantly elevated by P3 surgical incision ( $p=0.008$; Fisher's exact test;
Fig. 9B). This population included neurons which received a combination of monosynaptic input from both LT A-fibers and low-threshold C-fibers ( $n=3$; Fig. $4 C)$. Although a greater sample size is needed to conduct rigorous statistical analyses of the prevalence (and strength) of every individual subtype of primary afferent synaptic input, the available evidence suggests that the enhanced low-threshold transmission predominantly reflects an increase in LT A-fiber input, as 51\% (18/35) of lamina I projection neurons in the neonatally injured mice received monosynaptic input from this population compared with $20 \%$ (7/35) in naive littermate controls ( $p=0.012$; Fisher's exact test), while no significant differences were observed in the prevalence of LT C-fiber input to this population (Naive: 6 of 35; P3 Incision: 8 of $35 ; p=0.766$; data not shown).

Early tissue damage compromises feedforward inhibition of lamina I projection neurons following sensory input to the adult dorsal horn

Our previous work has documented selective deficits in spontaneous glycinergic transmission in lamina II of the adult mouse spinal cord following hindpaw surgical incision at P3 (Li et al., 2013). However, this study did not address the key question of whether neonatal injury reduces the level of synaptic inhibition that ultimately impinges upon ascending projection neurons following primary afferent input to the mature superficial dorsal horn (i.e., "feedforward inhibition"; Buzsáki, 1984; Nakatsuka et al., 2005; Lu et al., 2013). To address this issue, high-threshold electrical stimulation of the dorsal root was used to evoke polysynaptic IPSCs in adult projection neurons, and the IPSC was dissected into its composite subtypes by the bath application of gabazine to block $\mathrm{GABA}_{\mathrm{A}} \mathrm{Rs}$ and strychnine to block glycine receptors (Fig. 10A) as described previously (Baccei and Fitzgerald, 2004). P3 injury significantly decreased the efficacy of primary afferent-evoked glycinergic input onto adult projection neurons by $\sim 66 \%$ (Naive: $n=24$; Incision: $n=22$; $p=0.005$; MannWhitney test; Fig. 10B). Surprisingly, neonatal tissue damage also caused a reduction in the strength of $\mathrm{GABA}_{\mathrm{A}} \mathrm{R}$-mediated feedforward inhibition onto adult projection neurons (Naive: $n=22$; Incision: $n=20 ; p=0.033$; Mann-Whitney test; Fig. $10 C$ ).

To determine whether the reduced efficacy of feedforward inhibition was explained by deficits in the innervation of mature projection neurons by GABAergic and/or glycinergic neurons, we quantified the effect of neonatal hindpaw incision on the number of axonal boutons exhibiting immunoreactivity for the vesicular GABA transporter VGAT or the glycine transporter GlyT2 (Puskár et al., 2001) that were in apposition to adult lamina I neurons back-labeled with CTB injected into the brain (Fig. $11 A-C)$. There were no significant differences in the overall density of VGAT-positive boutons onto lamina I projection neurons between the naive ( $n=8$ cells) and neonatally incised groups $(n=7 ; p=0.787$; unpaired $t$ test; Fig. $11 D$, left). In addition, a similar density of VGAT-positive contacts was observed at the soma (Naive: $17.2 \pm 1.6$ contacts per $1000 \mu \mathrm{m}^{2}$; P3 Incision: $15.9 \pm 2.0 ; p=0.611$; unpaired $t$ test) and dendrites (Naive: $32.7 \pm 3.9$ contacts per $1000 \mu \mathrm{m}^{2}$; P3 Incision: $30.8 \pm 3.6$; $p=$ 0.728 ) in the two groups (data not shown). Neonatal tissue damage also failed to significantly change the number of glycinergic terminals contacting adult projection neurons as measured by the overall density of GlyT2-positive puncta (Naive: $n=17$; P3 Incision: $n=10 ; p=0.538$; unpaired $t$ test; Fig. $11 D$, right), as well as the density measured at the soma (Naive: $5.7 \pm 0.5$ contacts per $1000 \mu \mathrm{m}^{2}$; P3 Incision: $\left.6.1 \pm 1.2 ; p=0.75\right)$ or dendrites 

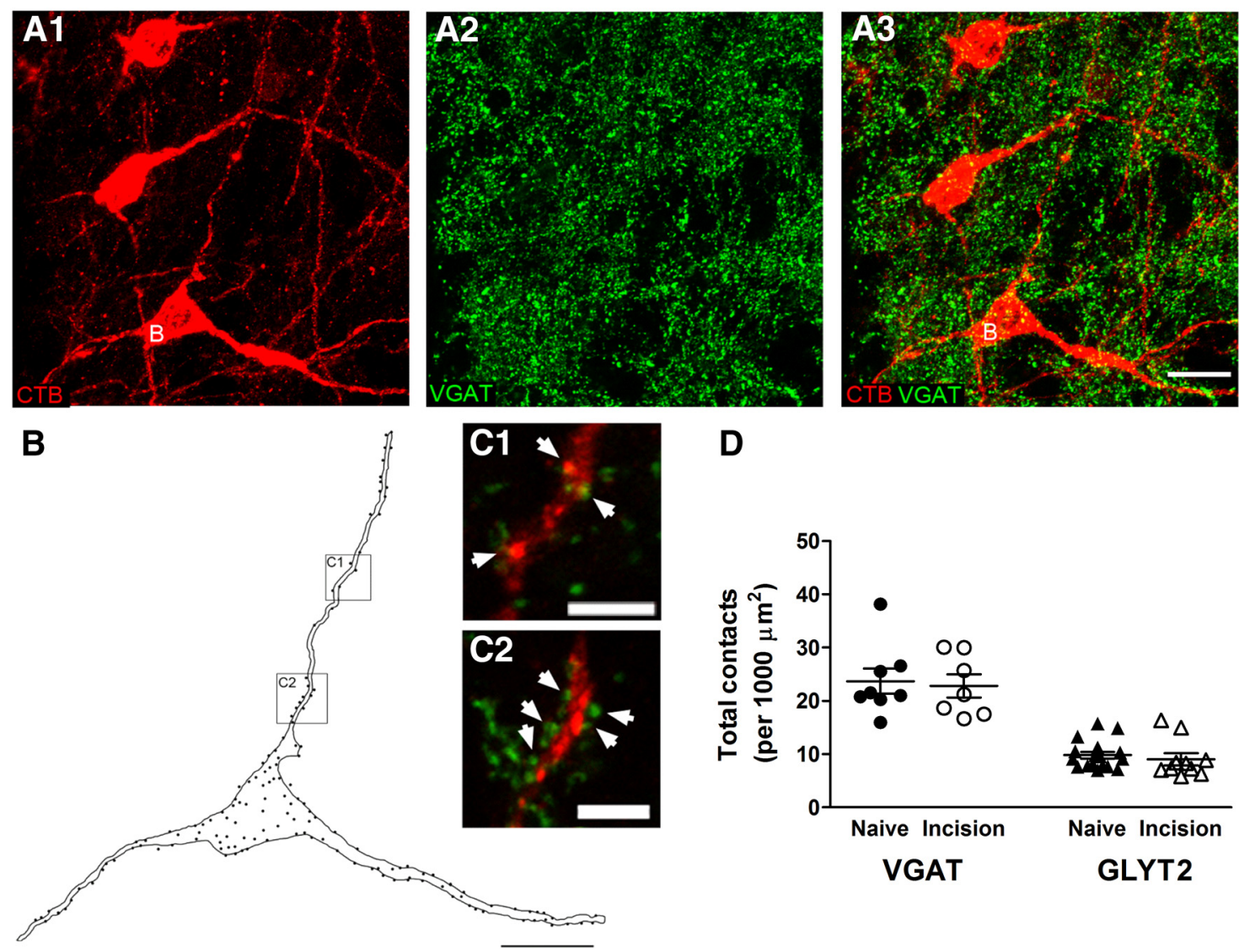

D

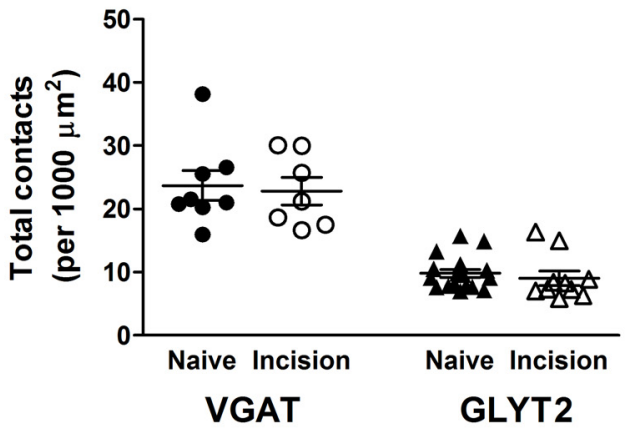

Figure 11. Early surgical injury does not disrupt the GABAergic and glycinergic innervation of lamina I projection neurons in the adult spinal cord. $A$, Representative images of VGAT-IR puncta (green) in apposition to mature lamina I projection neurons (red) identified via the retrograde transport of (TB injected into the brain. Images represent a projection of a $z$-stack series of 16 optical sections at $0.5 \mu \mathrm{m} z$-separation. Neuron labeled " $B$ " was selected for quantification. Scale bar, $20 \mu \mathrm{m}$. B, Drawing of a projection neuron (highlighted in $A$ ) showing the locations of VGAT-IR axonal boutons in close apposition to the dendrites and soma. Each dot represents a single axonal bouton. Scale bar, $20 \mu \mathrm{m}$. C, Higher-magnification of boxed regions in $\boldsymbol{B}$ showing several VGAT-positive contacts (green) onto the dendrites of the projection neuron (arrowheads). Panels correspond to single optical sections $(0.5 \mu \mathrm{m}$ thickness) from the $z$-stack used in $\boldsymbol{A}$. Scale bars, $5 \mu \mathrm{m}$. $\boldsymbol{D}$, Plot illustrating that surgical incision at P3 failed to alter the overall density of putative contacts between VGAT-positive ( $p=0.787$; unpaired $t$ test; left) or GlyT2-positive ( $p=0.538$; unpaired $t$ test; right) boutons and lamina I projection neurons during adulthood.

(Naive: $15.9 \pm 1.6$ contacts per $1000 \mu \mathrm{m}^{2}$; P3 Incision: $13.4 \pm$ $1.3 ; p=0.283$; data not shown).

\section{Neonatal injury enhances the gain of nociceptive transmission onto spino-parabrachial neurons in the adult spinal cord}

The observed changes in synaptic signaling onto mature lamina I projection neurons after neonatal tissue damage are likely to influence pain sensitivity only if they also result in altered action potential discharge in these key output neurons of the spinal nociceptive circuit. Therefore, we next investigated the extent to which early injury modulated the integration of primary afferentevoked synaptic inputs and the subsequent transformation of these inputs into action potential discharge within adult lamina I projection neurons. Mature spino-parabrachial neurons could be divided into two classes based on their firing properties in response to in vitro electrical stimulation of the dorsal root. A subset of projection neurons fired no more than a single action potential regardless of the stimulation intensity (Fig. 12A), whereas other cells exhibited higher firing frequencies with increasing stimulation of the dorsal root (Fig. 12B). Importantly, the adult lamina I projection neurons which were capable of firing repetitively demonstrated a greater level of action potential discharge in response to primary afferent stimulation when preceded by neonatal hindpaw incision (Naive: $n=10$; Incision: $n=$
8; $p<0.0001$; two-way ANOVA), which was particularly apparent at lower stimulus intensities (Fig. 12D). A significant leftward shift in the stimulus-response relationship after early injury was also observed in the group of single-spiking projection neurons (Naive: $n=5$; Incision: $n=7 ; p=0.004$; two-way ANOVA; Fig. $12 C)$. These changes occurred in the absence of injury-evoked alterations in the resting membrane potential of the projection neurons (Naive: $-78.8 \pm 1.7 \mathrm{mV}, n=15$; Incision: $-78.5 \pm 1.7$ $\mathrm{mV}, n=15 ; p=0.41$; unpaired $t$ test).

\section{Discussion}

The present results demonstrate, for the first time, that tissue damage during the neonatal period has long-term consequences for synaptic integration and membrane excitability within adult lamina I projection neurons, which represent a major output of the spinal nociceptive network and are essential for the generation of inflammatory and neuropathic hyperalgesia (Mantyh et al., 1997; Nichols et al., 1999). The data also point to a persistent reorganization in the distribution of primary afferent synaptic inputs to mature projection neurons following early surgical injury. The resulting shift in the transformation of sensory inputs into action potential discharge by these projection neurons is predicted to enhance the gain of ascending nociceptive transmission to the brain, and thus represents a novel potential mecha- 
nism by which the mature superficial dorsal horn network may be "primed" by neonatal tissue damage.

It seems highly likely that the increased firing of adult lamina I projection neurons in response to sensory input (Fig. 12) reflects, at least in part, a prolonged disruption in the normal balance between synaptic excitation and inhibition onto these cells, as an increased efficacy of primary afferent synapses (Fig. 1) is accompanied by a reduction in afferent-evoked (i.e., feedforward) inhibition (Fig. 10). The observed deficits in both glycinergic and GABAergic feedforward inhibition are interesting in light of our previous work suggesting that neonatal hindpaw incision selectively compromised GlyRmediated signaling within lamina II of the adult mouse SDH (Li et al., 2013). Although the underlying mechanisms remain to be elucidated, the available evidence argues against a reduced innervation of projection neurons by local GABAergic and glycinergic neurons (Fig. 11). Alternatively, because the inhibitory synaptic networks of the dorsal horn undergo significant maturation during the early postnatal period (Keller et al., 2001; Baccei and Fitzgerald, 2004; Cordero-Erausquin et al., 2005; Bremner and Fitzgerald, 2008; Koch et al., 2012), aberrant sensory input resulting from early surgical injury could interfere with the normal trafficking of $\mathrm{GABA}_{\mathrm{A}}$ Rs and GlyRs to appropriate sites on the postsynaptic membrane (Charrier et al., 2010; Niwa et al., 2012). Another possibility is that the documented reduction in the intrinsic membrane excitability of GABAergic lamina II neurons in the adult spinal cord after early injury (Li and Baccei, 2014) results in the activation of fewer inhibitory interneurons following sensory input to the SDH and a subsequent reduction in polysynaptic inhibitory transmission onto mature lamina I projection neurons.

It should be noted that the present investigation selectively focused on lamina I neurons which project to the PB. Although $\sim 80 \%$ of all lamina I projection neurons target the $\mathrm{PB}$ and spinoPAG and spino-thalamic neurons represent a subset of the larger spino-PB population (Spike et al., 2003), there are important functional differences between the spino-PB and spino-PAG populations in terms of their intrinsic membrane properties (Ruscheweyh et al., 2004), synaptic inputs (Dahlhaus et al., 2005), and susceptibility to synaptic long-term potentiation (LTP; Ikeda et al., 2006). Therefore, the effects of neonatal incision on synaptic integration and afferentevoked firing could vary across different populations of projection neurons. It will also be important to determine whether neonatal tissue damage can evoke persistent modifications in the properties of activity-dependent plasticity at nociceptive synapses onto different classes of mature lamina I projection neurons. Indeed, an enhancement of LTP after early injury might be predicted given that feedforward inhibition of projection neurons is significantly reduced (Fig. 10) and LTP in the SDH is
B
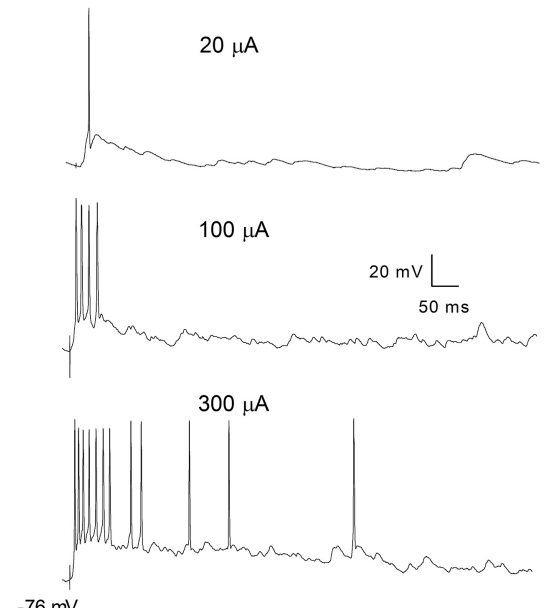

D

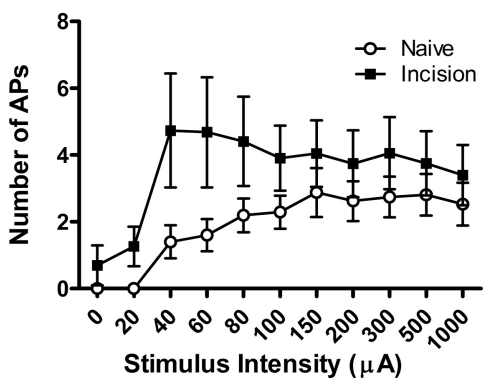

Figure 12. Adult lamina I projection neurons exhibit greater action potential discharge in response to sensory input when preceded by neonatal tissue damage. $\boldsymbol{A}$, Example of a spino-parabrachial neuron that discharged a single action potential (AP) from its resting membrane potential regardless of the intensity of dorsal root stimulation. $\boldsymbol{B}$, Other projection neurons responded ncision led to a significant leftward shift in the stimulus-response function in both the single-spiking ( $p=0.004$; two-way ANOVA; $)$, and repetitive-firing ( $p<0.0001$; two-way ANOVA; D) subtypes of adult lamina I projection neurons.

strongly influenced by inhibitory signaling within the region (Ikeda et al., 2000; Hu et al., 2006).

Whereas prior studies of synaptic signaling onto lamina I projection neurons have understandably focused on high-threshold (i.e., A $\delta$ - and C-fiber) primary afferent inputs, our electrophysiological results argue that adult mouse projection neurons are also directly innervated by low-threshold fibers that exhibit conduction velocities in the unmyelinated range (Fig. 4). Lowthreshold C-fiber mechanoreceptors (C-LTMRs) have been documented in a variety of species including humans, cats and rodents, where they are predominantly localized to hairy skin and are thought to encode pleasurable touch under normal conditions (Bessou and Perl, 1969; Hahn, 1971; Shea and Perl, 1985; Vallbo et al., 1999; Löken et al., 2009; Seal et al., 2009). Indeed, rat lamina I spino-PB neurons (identified via antidromic stimulation) have been shown to receive input from C-LTMRs in vivo (Andrew, 2010), although extracellular single unit recordings do not allow for the determination of whether such inputs are monosynaptic or polysynaptic in nature. The existence of direct C-LTMR inputs to ascending projection neurons is supported by the present observation that axonal boutons exhibiting immunoreactivity for VGLUT3, a known marker of the C-LTMR population (Seal et al., 2009), form putative synaptic contacts onto back-labeled spino-PB neurons (Fig. 7). The increased mEPSC frequency following TRPM8 activation (Fig. 8) also supports this 
notion, given the close association between VGLUT3 and TRPM8 in mouse sensory neurons (Draxler et al., 2014). Collectively, the elevation in glutamate release in response to TRPM8 and TRPV1 agonists suggests that mature projection neurons receive direct synaptic input from nociceptive afferents which include those sensitive to temperature.

Perhaps more surprisingly, we also find evidence that adult projection neurons receive monosynaptic input from lowthreshold afferents conducting in the A-fiber range (Fig. 4). The onset latencies and stimulus thresholds of the fastest EPSCs (Fig. 5) are consistent with the possibility that they are mediated by $\mathrm{A} \beta$-fibers. To our knowledge, there is no anatomical evidence showing that lamina I receives projections from $\mathrm{A} \beta$ lowthreshold mechanoreceptors (A $\beta$ LTMRs) in the adult rodent. Ex vivo phenotyping of sensory neurons suggests that slowly adapting $\mathrm{A} \beta$ LTMRs project to lamina $\mathrm{II}_{\mathrm{i}}-\mathrm{V}$ of the dorsal horn in adult mice (Woodbury and Koerber, 2007). Similarly, recent genetic labeling of the rapidly adapting $\mathrm{A} \beta \mathrm{LTMR}$ population via the Npy2r promoter revealed central terminations that were restricted to laminae III-V (Li et al., 2011). This is in general agreement with our observations that axonal boutons immunopositive for VGLUT1, a marker of large, myelinated proprioceptors and innocuous mechanoreceptors (Todd et al., 2003; Alvarez et al., 2004; Yasaka et al., 2014), rarely contacted adult lamina I projection neurons (Fig. 7G,H). This apparent contradiction may be explained by a significant limitation of the in vitro spinal cord slice preparation, namely that the peripheral terminals (i.e., the site of sensory transduction) have been lost, preventing the functional identification of the primary afferent mediating the observed synaptic response. As a result, afferents that are recruited by low-intensity electrical stimulation of the dorsal root in vitro may selectively respond to noxious stimulation of its peripheral receptive field in vivo. Indeed, a significant proportion (up to $50 \%$ ) of A-fiber nociceptors in the mouse, rat and cat correspond to $A \beta$-fibers (Djouhri and Lawson, 2004), with a particularly close association between $\mathrm{A} \beta$ nociceptors and moderate pressure receptors (Burgess and Perl, 1967; Burgess et al., 1968; Woodbury and Koerber, 2003). Unfortunately, a biochemical marker of $A \beta$ nociceptors has yet to be identified, thus precluding an immunohistochemical analysis of their synaptic inputs to lamina I projection neurons.

Nonetheless, the data point to a long-term reorganization in the distribution of primary afferent inputs to adult projection neurons as the result of neonatal tissue injury, with a significant increase in the prevalence of spino-parabrachial neurons which were directly innervated by low-threshold primary afferents (Fig. 9). This may explain the enhanced action potential discharge in adult projection neurons in response to dorsal root stimulation in neonatally incised mice, which was particularly evident at lower stimulus intensities (Fig. 12). The present data suggest that the increased prevalence of low-threshold input to ascending projection neurons is most likely mediated by A-fibers, as the fraction of projection neurons receiving monosynaptic input from this population increased by $>2$-fold following neonatal incision. If these afferents do correspond to $\mathrm{A} \beta$-fibers associated with moderate pressure receptors, increased synaptic input from these fibers to projection neurons could potentiate ascending nociceptive transmission and therefore contribute to mechanical hypersensitivity under pathological conditions. However, it should be noted that our analysis of the strength of primary afferent synapses onto the spino-parabrachial neurons was conducted on pooled data from the various afferent subtypes, and thus we cannot rule out the possibility that a greater efficacy of low-threshold C-fiber connections onto lamina I projection neu- rons after neonatal injury also makes an important contribution to the greater action potential firing seen with low-intensity stimulation of the dorsal root. This would be interesting given that C-LTMRs expressing VGLUT3 are important for the generation of mechanical allodynia following peripheral nerve damage (Seal et al., 2009).

In conclusion, we speculate that the observed changes in synaptic integration within mature projection neurons following neonatal tissue damage lead to a prolonged increase in the amplification factor (i.e., gain) of the spinal pain network. This is predicted to result in a significant potentiation of ascending nociceptive transmission to the brain following subsequent noxious stimulation, such as that which occurs following a second injury later in life. Therefore, these persistent changes in synaptic function within the adult superficial dorsal horn could contribute to the priming of developing pain pathways following tissue injury during the early postnatal period.

\section{References}

Alvarez FJ, Villalba RM, Zerda R, Schneider SP (2004) Vesicular glutamate transporters in the spinal cord, with special reference to sensory primary afferent synapses. J Comp Neurol 472:257-280. CrossRef Medline

Andrew D (2010) Quantitative characterization of low-threshold mechanoreceptor inputs to lamina I spinoparabrachial neurons in the rat. J Physiol 588:117-124. CrossRef Medline

Baccei ML, Fitzgerald M (2004) Development of GABAergic and glycinergic transmission in the neonatal rat dorsal horn. J Neurosci 24:4749-4757. CrossRef Medline

Baccei ML, Bardoni R, Fitzgerald M (2003) Development of nociceptive synaptic inputs to the neonatal rat dorsal horn: glutamate release by capsaicin and menthol. J Physiol 549:231-242. CrossRef Medline

Beggs S, Currie G, Salter MW, Fitzgerald M, Walker SM (2012) Priming of adult pain responses by neonatal pain experience: maintenance by central neuroimmune activity. Brain 135:404-417. CrossRef Medline

Berry MS, Pentreath VW (1976) Criteria for distinguishing between monosynaptic and polysynaptic transmission. Brain Res 105:1-20. CrossRef Medline

Bessou P, Perl ER (1969) Response of cutaneous sensory units with unmyelinated fibers to noxious stimuli. J Neurophysiol 32:1025-1043. Medline

Birren JE, Wall PD (1956) Age changes in conduction velocity, refractory period, number of fibers, connective tissue space and blood vessels in sciatic nerve of rats. J Comp Neurol 104:1-16. CrossRef Medline

Bremner LR, Fitzgerald M (2008) Postnatal tuning of cutaneous inhibitory receptive fields in the rat. J Physiol 586:1529-1537. CrossRef Medline

Brennan TJ, Vandermeulen EP, Gebhart GF (1996) Characterization of a rat model of incisional pain. Pain 64:493-501. CrossRef Medline

Burgess PR, Perl ER (1967) Myelinated afferent fibres responding specifically to noxious stimulation of the skin. J Physiol 190:541-562. CrossRef Medline

Burgess PR, Petit D, Warren RM (1968) Receptor types in cat hairy skin supplied by myelinated fibers. J Neurophysiol 31:833-848. Medline

Buzsáki G (1984) Feed-forward inhibition in the hippocampal formation. Prog Neurobiol 22:131-153. CrossRef Medline

Carbajal R, Rousset A, Danan C, Coquery S, Nolent P, Ducrocq S, Saizou C, Lapillonne A, Granier M, Durand P, Lenclen R, Coursol A, Hubert P, de Saint Blanquat L, Boëlle PY, Annequin D, Cimerman P, Anand KJ, Bréart G (2008) Epidemiology and treatment of painful procedures in neonates in intensive care units. JAMA 300:60-70. CrossRef Medline

Carlstedt T (1977) Observations on the morphology at the transition between the peripheral and the central nervous system in the cat: I. A preparative procedure useful for electron microscopy of the lumbosacral dorsal. Acta Physiol Scand Suppl 446:5-22. Medline

Charrier C, Machado P, Tweedie-Cullen RY, Rutishauser D, Mansuy IM, Triller A (2010) A crosstalk between betal and beta3 integrins controls glycine receptor and gephyrin trafficking at synapses. Nat Neurosci 13: 1388-1395. CrossRef Medline

Chu YC, Chan KH, Tsou MY, Lin SM, Hsieh YC, Tao YX (2007) Mechanical pain hypersensitivity after incisional surgery is enhanced in rats subjected to neonatal peripheral inflammation: effects of $N$-methyl-D-aspartate receptor antagonists. Anesthesiology 106:1204-1212. CrossRef Medline 
Cordero-Erausquin M, Coull JA, Boudreau D, Rolland M, De Koninck Y (2005) Differential maturation of GABA action and anion reversal potential in spinal lamina I neurons: impact of chloride extrusion capacity. J Neurosci 25:9613-9623. CrossRef Medline

Dahlhaus A, Ruscheweyh R, Sandkühler J (2005) Synaptic input of rat spinal lamina I projection and unidentified neurones in vitro. J Physiol 566: 355-368. CrossRef Medline

Dengler-Crish CM, Bruehl S, Walker LS (2011) Increased wind-up to heat pain in women with a childhood history of functional abdominal pain. Pain 152:802-808. CrossRef Medline

Djouhri L, Lawson SN (2004) A $\beta$-fiber nociceptive primary afferent neurons: a review of incidence and properties in relation to other afferent A-fiber neurons in mammals. Brain Res Brain Res Rev 46:131-145. CrossRef Medline

Draxler P, Honsek SD, Forsthuber L, Hadschieff V, Sandkühler J (2014) VGluT3(+) primary afferents play distinct roles in mechanical and cold hypersensitivity depending on pain etiology. J Neurosci 34:12015-12028. CrossRef Medline

Hahn JF (1971) Thermal-mechanical stimulus interactions in lowthreshold C-fiber mechanoreceptors of cat. Exp Neurol 33:607-617. CrossRef Medline

Hermann C, Hohmeister J, Demirakça S, Zohsel K, Flor H (2006) Longterm alteration of pain sensitivity in school-aged children with early pain experiences. Pain 125:278-285. CrossRef Medline

Hu XD, Ge YX, Hu NW, Zhang HM, Zhou LJ, Zhang T, Li WM, Han YF, Liu XG (2006) Diazepam inhibits the induction and maintenance of LTP of C-fiber evoked field potentials in spinal dorsal horn of rats. Neuropharmacology 50:238-244. CrossRef Medline

Ikeda H, Asai T, Murase K (2000) Robust changes of afferent-induced excitation in the rat spinal dorsal horn after conditioning high-frequency stimulation. J Neurophysiol 83:2412-2420. Medline

Ikeda H, Heinke B, Ruscheweyh R, Sandkühler J (2003) Synaptic plasticity in spinal lamina I projection neurons that mediate hyperalgesia. Science 299:1237-1240. CrossRef Medline

Ikeda H, Stark J, Fischer H, Wagner M, Drdla R, Jäger T, Sandkühler J (2006) Synaptic amplifier of inflammatory pain in the spinal dorsal horn. Science 312:1659-1662. CrossRef Medline

Keller AF, Coull JA, Chery N, Poisbeau P, De Koninck Y (2001) Regionspecific developmental specialization of GABA-glycine cosynapses in laminas I-II of the rat spinal dorsal horn. J Neurosci 21:7871-7880. Medline

Koch SC, Tochiki KK, Hirschberg S, Fitzgerald M (2012) C-fiber activitydependent maturation of glycinergic inhibition in the spinal dorsal horn of the postnatal rat. Proc Natl Acad Sci U S A 109:12201-12206. CrossRef Medline

Koltzenburg M, Stucky CL, Lewin GR (1997) Receptive properties of mouse sensory neurons innervating hairy skin. J Neurophysiol 78:1841-1850. Medline

LaPrairie JL, Murphy AZ (2007) Female rats are more vulnerable to the long-term consequences of neonatal inflammatory injury. Pain 132: S124-S133. CrossRef Medline

Li J, Baccei ML (2012) Developmental regulation of membrane excitability in rat spinal lamina I projection neurons. J Neurophysiol 107:2604-2614. CrossRef Medline

Li J, Baccei ML (2014) Neonatal tissue injury reduces the intrinsic excitability of adult mouse superficial dorsal horn neurons. Neuroscience 256: 392-402. CrossRef Medline

Li J, Blankenship ML, Baccei ML (2013) Deficits in glycinergic inhibition within adult spinal nociceptive circuits after neonatal tissue damage. Pain 154:1129-1139. CrossRef Medline

Li L, Rutlin M, Abraira VE, Cassidy C, Kus L, Gong S, Jankowski MP, Luo W, Heintz N, Koerber HR, Woodbury CJ, Ginty DD (2011) The functional organization of cutaneous low-threshold mechanosensory neurons. Cell 147:1615-1627. CrossRef Medline

Löken LS, Wessberg J, Morrison I, McGlone F, Olausson H (2009) Coding of pleasant touch by unmyelinated afferents in humans. Nat Neurosci 12:547-548. CrossRef Medline

Lu Y, Dong H, Gao Y, Gong Y, Ren Y, Gu N, Zhou S, Xia N, Sun YY, Ji RR, Xiong L (2013) A feed-forward spinal cord glycinergic neural circuit gates mechanical allodynia. J Clin Invest 123:4050-4062. CrossRef Medline

Mantyh PW, Rogers SD, Honore P, Allen BJ, Ghilardi JR, Li J, Daughters RS,
Lappi DA, Wiley RG, Simone DA (1997) Inhibition of hyperalgesia by ablation of lamina I spinal neurons expressing the substance $\mathrm{P}$ receptor. Science 278:275-279. CrossRef Medline

Nakatsuka T, Chen M, Takeda D, King C, Ling J, Xing H, Ataka T, Vierck C, Yezierski R, Gu JG (2005) Substance P-driven feed-forward inhibitory activity in the mammalian spinal cord. Mol Pain 1:20. CrossRef Medline

Nichols ML, Allen BJ, Rogers SD, Ghilardi JR, Honore P, Luger NM, Finke MP, Li J, Lappi DA, Simone DA, Mantyh PW (1999) Transmission of chronic nociception by spinal neurons expressing the substance P receptor. Science 286:1558-1561. CrossRef Medline

Niwa F, Bannai H, Arizono M, Fukatsu K, Triller A, Mikoshiba K (2012) Gephyrin-independent GABA(A)R mobility and clustering during plasticity. PLoS One 7:e36148. CrossRef Medline

Paxinos G, Franklin KBJ (2012) The mouse brain in stereotaxic coordinates, Ed 4. London: Academic.

Peng YB, Ling QD, Ruda MA, Kenshalo DR (2003) Electrophysiological changes in adult rat dorsal horn neurons after neonatal peripheral inflammation. J Neurophysiol 90:73-80. CrossRef Medline

Pinto V, Szûcs P, Derkach VA, Safronov BV (2008) Monosynaptic convergence of $\mathrm{C}$ - and $\mathrm{a} \delta$-afferent fibres from different segmental dorsal roots on to single substantia gelatinosa neurones in the rat spinal cord. J Physiol 586:4165-4177. CrossRef Medline

Polgár E, Watanabe M, Hartmann B, Grant SG, Todd AJ (2008) Expression of AMPA receptor subunits at synapses in laminae I-III of the rodent spinal dorsal horn. Mol Pain 4:5. CrossRef Medline

Puskár Z, Polgár E, Todd AJ (2001) A population of large lamina I projection neurons with selective inhibitory input in rat spinal cord. Neuroscience 102:167-176. CrossRef Medline

Ren K, Anseloni V, Zou SP, Wade EB, Novikova SI, Ennis M, Traub RJ, Gold MS, Dubner R, Lidow MS (2004) Characterization of basal and reinflammation-associated long-term alteration in pain responsivity following short-lasting neonatal local inflammatory insult. Pain 110:588-596. CrossRef Medline

Rose HJ, Metherate R (2005) Auditory thalamocortical transmission is reliable and temporally precise. J Neurophysiol 94:2019-2030. CrossRef Medline

Ruscheweyh R, Ikeda H, Heinke B, Sandkühler J (2004) Distinctive membrane and discharge properties of rat spinal lamina I projection neurones in vitro. J Physiol 555:527-543. CrossRef Medline

Ruscheweyh R, Forsthuber L, Schoffnegger D, Sandkühler J (2007) Modification of classical neurochemical markers in identified primary afferent neurons with $\mathrm{A} \beta-$, a $\delta$-, and C-fibers after chronic constriction injury in mice. J Comp Neurol 502:325-336. CrossRef Medline

Seal RP, Wang X, Guan Y, Raja SN, Woodbury CJ, Basbaum AI, Edwards RH (2009) Injury-induced mechanical hypersensitivity requires C-low threshold mechanoreceptors. Nature 462:651-655. CrossRef Medline

Shea VK, Perl ER (1985) Sensory receptors with unmyelinated (C) fibers innervating the skin of the rabbit's ear. J Neurophysiol 54:491-501. Medline

Shreckengost J, Calvo J, Quevedo J, Hochman S (2010) Bicucullinesensitive primary afferent depolarization remains after greatly restricting synaptic transmission in the mammalian spinal cord. J Neurosci 30:52835288. CrossRef Medline

Spike RC, Puskár Z, Andrew D, Todd AJ (2003) A quantitative and morphological study of projection neurons in lamina I of the rat lumbar spinal cord. Eur J Neurosci 18:2433-2448. CrossRef Medline

Stevens B, McGrath P, Gibbins S, Beyene J, Breau L, Camfield C, Finley A, Franck L, Howlett A, McKeever P, O’Brien K, Ohlsson A, Yamada J (2003) Procedural pain in newborns at risk for neurologic impairment. Pain 105:27-35. CrossRef Medline

Thomas PK, Ochoa J, Berthold CH, Carlstedt T, Corneliuson O (1993) Microscopic anatomy of peripheral nervous system. In: Peripheral neuropathy (Dyck PJ, Thomas PK, Griffin JW, Low PA, Poduslo JF, eds). Philadelphia: WB Saunders.

Ting JT, Chen Q, Feng G. Improved methods for acute brain slice preparation from adult and aging animals. Soc Neurosci Abstracts 2011;520.29.

Todd AJ, Puskar Z, Spike RC, Hughes C, Watt C, Forrest L (2002) Projection neurons in lamina $I$ of rat spinal cord with the neurokinin 1 receptor are selectively innervated by substance p-containing afferents and respond to noxious stimulation. J Neurosci 22:4103-4113. Medline

Todd AJ, Hughes DI, Polgár E, Nagy GG, Mackie M, Ottersen OP, Maxwell DJ (2003) The expression of vesicular glutamate transporters VGLUT1 and 
VGLUT2 in neurochemically defined axonal populations in the rat spinal cord with emphasis on the dorsal horn. Eur J Neurosci 17:13-27. CrossRef Medline

Torsney C, Fitzgerald M (2003) Spinal dorsal horn cell receptive field size is increased in adult rats following neonatal hindpaw skin injury. J Physiol 550:255-261. CrossRef Medline

Torsney C, MacDermott AB (2006) Disinhibition opens the gate to pat hological pain signaling in superficial neurokinin 1 receptor-expressing neurons in rat spinal cord. J Neurosci 26:1833-1843. CrossRef Medline

Vallbo AB, Olausson H, Wessberg J (1999) Unmyelinated afferents constitute a second system coding tactile stimuli of the human hairy skin. J Neurophysiol 81:2753-2763. Medline

Waddell PJ, Lawson SN, McCarthy PW (1989) Conduction velocity changes along the processes of rat primary sensory neurons. Neuroscience 30:577-584. CrossRef Medline

Walker LS, Dengler-Crish CM, Rippel S, Bruehl S (2010) Functional abdominal pain in childhood and adolescence increases risk for chronic pain in adulthood. Pain 150:568-572. CrossRef Medline

Walker LS, Sherman AL, Bruehl S, Garber J, Smith CA (2012) Functional abdominal pain patient subtypes in childhood predict functional gastrointestinal disorders with chronic pain and psychiatric comorbidities in adolescence and adulthood. Pain 153:1798-1806. CrossRef Medline

Walker SM, Tochiki KK, Fitzgerald M (2009) Hindpaw incision in early life increases the hyperalgesic response to repeat surgical injury: critical pe- riod and dependence on initial afferent activity. Pain 147:99-106. CrossRef Medline

Watanabe M, Fukaya M, Sakimura K, Manabe T, Mishina M, Inoue Y (1998) Selective scarcity of NMDA receptor channel subunits in the stratum lucidum (mossy fibre-recipient layer) of the mouse hippocampal CA3 subfield. Eur J Neurosci 10:478-487. CrossRef Medline

Wollgarten-Hadamek I, Hohmeister J, Demirakça S, Zohsel K, Flor H, Hermann C (2009) Do burn injuries during infancy affect pain and sensory sensitivity in later childhood? Pain 141:165-172. CrossRef Medline

Woodbury CJ, Koerber HR (2003) Widespread projections from myelinated nociceptors throughout the substantia gelatinosa provide novel insights into neonatal hypersensitivity. J Neurosci 23:601-610. Medline

Woodbury CJ, Koerber HR (2007) Central and peripheral anatomy of slowly adapting type I low-threshold mechanoreceptors innervating trunk skin of neonatal mice. J Comp Neurol 505:547-561. CrossRef Medline

Yamashita M (1986) Monosynaptic connexions of low threshold muscle afferents with hindlimb motoneurones in the turtle spinal cord. Exp Brain Res 63:519-529. CrossRef Medline

Yasaka T, Tiong SY, Polgár E, Watanabe M, Kumamoto E, Riddell JS, Todd AJ (2014) A putative relay circuit providing low-threshold mechanoreceptive input to lamina I projection neurons via vertical cells in lamina II of the rat dorsal horn. Mol Pain 10:3. CrossRef Medline 